\title{
Organometallic Nanoparticles Ligated by NHCs: Synthesis, Surface Chemistry and Ligand Effects
}

\author{
Christian Cerezo-Navarrete ${ }^{1(D)}$, Patricia Lara ${ }^{2, *(\mathbb{D})}$ and Luis M. Martínez-Prieto ${ }^{1, *(D)}$ \\ 1 ITQ, Instituto de Tecnología Química, Universitat Politècnica de València (UPV), Av. de los Naranjos S/N, \\ 46022 Valencia, Spain; chcena@posgrado.upv.es \\ 2 Instituto de Investigaciones Químicas (IIQ), Departamento de Química Inorgánica and Centro de Innovación \\ en Química Avanzada (ORFEO-CINQA), CSIC—Universidad de Sevilla, 41092 Sevilla, Spain \\ * Correspondence: patricia@iiq.csic.es (P.L.); luismiguel.martinez@csic.es (L.M.M.-P.)
}

Received: 23 September 2020; Accepted: 30 September 2020; Published: 3 October 2020

\begin{abstract}
Over the last 20 years, the use of metallic nanoparticles (MNPs) in catalysis has awakened a great interest in the scientific community, mainly due to the many advantages of this kind of nanostructures in catalytic applications. MNPs exhibit the characteristic stability of heterogeneous catalysts, but with a higher active surface area than conventional metallic materials. However, despite their higher activity, MNPs present a wide variety of active sites, which makes it difficult to control their selectivity in catalytic processes. An efficient way to modulate the activity/selectivity of MNPs is the use of coordinating ligands, which transforms the MNP surface, subsequently modifying the nanoparticle catalytic properties. In relation to this, the use of $\mathrm{N}$-heterocyclic carbenes (NHC) as stabilizing ligands has demonstrated to be an effective tool to modify the size, stability, solubility and catalytic reactivity of MNPs. Although NHC-stabilized MNPs can be prepared by different synthetic methods, this review is centered on those prepared by an organometallic approach. Here, an organometallic precursor is decomposed under $\mathrm{H}_{2}$ in the presence of non-stoichiometric amounts of the corresponding NHC-ligand. The resulting organometallic nanoparticles present a clean surface, which makes them perfect candidates for catalytic applications and surface studies. In short, this revision study emphasizes the great versatility of NHC ligands as MNP stabilizers, as well as their influence on catalysis.
\end{abstract}

Keywords: organometallic nanoparticles; $N$-heterocyclic carbenes; organometallic approach; surface chemistry; ligand effects; catalysis; hydrogenation reactions; H/D exchanges

\section{Introduction}

Since the beginning of this century, metallic nanoparticles (MNPs) have emerged in the field of chemistry as new nano-objects with a great potential in catalysis. The reason for this interest resides in the fact that they combine the advantages of homogeneous (molecular complexes) and heterogeneous (metals dispersed on supports) catalysts [1,2]. MNPs present the distinctive stability of heterogeneous catalysts, but with a higher active surface area. Due to their characteristic small size (between 1 and $100 \mathrm{~nm}$ ), MNPs present a high proportion of surface atoms, which results in a large number of active centers that facilitate the catalyst-substrate interactions. However, this great number of active surface sites normally convert the substrates in different ways; therefore, to achieve a precise control of MNP selectivity is crucial in this emerging field. An effective way to control the reactivity and selectivity of MNPs is by using ancillary ligands as stabilizers. As well as in organometallic chemistry, coordinating ligands are able to alter the steric and electronic properties of the metallic surface, and thus to change the MNP catalytic properties. Indeed, there are many parallels between ancillary ligands ligated to MNPs and molecular complexes [3]. For example, in both cases, 
ligands are usually chemically bound to the metal atoms through the donation of a free electron pair from the ligand (which behaves as a Lewis base) to the metal. In this context, $N$-heterocyclic carbenes (NHC) have appeared as efficient ligands for MNP stabilization, which not only can modify the size, stability, and solubility of MNPs, but also are able to modulate their catalytic reactivity.

NHCs have been extensively studied over the past 30 years [4,5]. Since Bertrand and Arduengo isolated and characterized the first example of this kind of neutral compounds (Figure 1a), its interest as a ligand has significantly increased [6,7]. The greater stability of NHC ligands in respect to other type of carbenes is mainly due to their specific electronic structure. The two adjacent $\mathrm{N}$ atoms to the carbenic carbon atom stabilize the empty $p$-orbital of the last one by electronic resonance and partially remove the electronic density from its occupied $\sigma$-orbital through the $\mathrm{C}-\mathrm{N}$ bonds (Figure 1b) [8]. Thanks to their specific electronic properties, NHCs present numerous advantages as ancillary ligands. For example, due to their electron-donating ability, these ligands strongly bind to transition metals. In addition, in contrast to phosphines, they do not easily oxidize as their chemical structure only contains $\mathrm{C}, \mathrm{H}$ and $\mathrm{N}$ atoms. As a result, NHCs have been promoted from a scientific curiosity to one of the most versatile ligands in coordination chemistry [9-11]. As excellent ligands for transition metal complexes, they have been applied in some of the most important catalytic processes in chemistry. The above-mentioned characteristic of NHCs not only make them perfect candidates for the formation of homogeneous catalysts, but also allow their use in MNP synthesis, showing a great ability to stabilize MNPs [12-16]. Indeed, during the last 10 years, NHC ligands have been employed to stabilize a considerable number of MNPs of different metals, such as Au [17], Pd [18,19], Ru [20] and Ir [21]. The great versatility of these stabilizing ligands has allowed the exploration of the influence of the structure of the NHCs (i.e., N-substituents and the groups bound on the backbone of the imidazolium ring) in the MNP properties, such as size, solubility, stability, surface state and reactivity. Therefore, it has been observed that the nature and the amount of NHC employed in the preparation of the MNPs have a clear influence and modify the physicochemical properties of NHC-stabilized MNPs. In other words, depending on the N-substituent (electron donor/acceptor or bulky groups), or the number of NHC equivalents used as stabilizer, the resulting MNPs will have different available active surface sites for catalysis, enabling to reach a precise control of the reactivity and selectivity of these colloids. For all this, MNPs stabilized with NHC ligands have been successfully used in many catalytic processes. Indeed, they have shown a high activity and selectivity in numerous hydrogenation reactions, specifically in the hydrogenation of aromatic and ketones groups [12-14,22]. Furthermore, NHC-based MNPs have also been applied in oxidation [13], hydroboration $[23,24]$ and deuteration $[25,26]$ reactions among others, making possible the study of the influence of the ligands in most of the cases.

a)

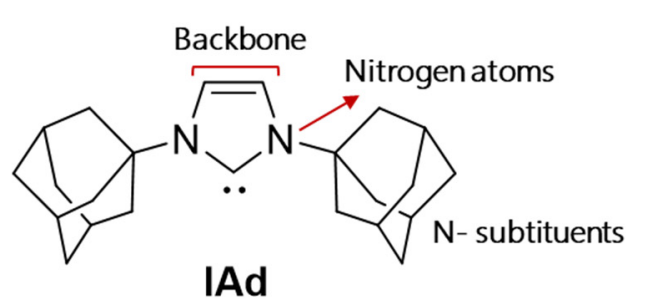

b)

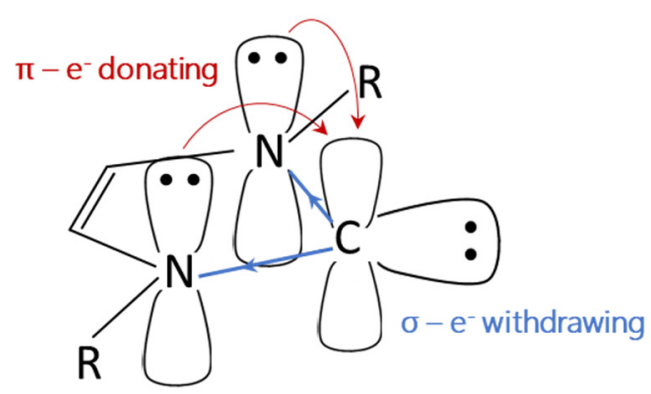

Figure 1. (a) First example of an isolated $N$-heterocyclic carbenes (NHC) ligand. (b) Electronic structure of an $\mathrm{N}$-heterocyclic carbene ligand.

NHC-stabilized MNPs have been mainly synthesized by direct decomposition of NHC-based metal complexes, by a ligand-exchange process, or by the reduction of a metal precursor in the presence of a selected NHC ligand. Within this latter, we can find the organometallic approach, consists in the controlled decomposition of a high-energy organometallic precursor under a reductive gas $\left(\mathrm{H}_{2}\right.$ or $\mathrm{CO}$ ) in the presence of a non-stoichiometric amount of an NHC ligand that controls the coalescence 
process (Figure 2). The organometallic approach has numerous advantages compared to the rest of the synthetic methods. First, the use of a pre-reduced organometallic complex permits the decomposition under mild conditions ( $\mathrm{H}_{2}$ pressure and room temperature), controlling the MNP growth, size and dispersion. Second, unlike the conventional MNP synthesis via chemical reduction, the non-utilization of secondary reducing agents allows obtaining MNPs with a clean surface, free of contaminants that can come from the reductant or the metal salt [27]. However, despite their numerous advantages, it is not a commonly used synthetic methodology due to the fact that it is necessary to employ an organometallic precursor, which is not always commercially available or requires a complex synthesis. Moreover, these organometallic precursors are usually very sensitive compounds that need to be stored and manipulated under inert atmosphere. Despite this fact, since the first describing of NHC-stabilized Ru nanoparticles [12], there has been a solid scientific line consisting in the development of the synthesis, surface studies and catalytic applications of MNPs ligated by NHCs obtained from an organometallic approach [28].

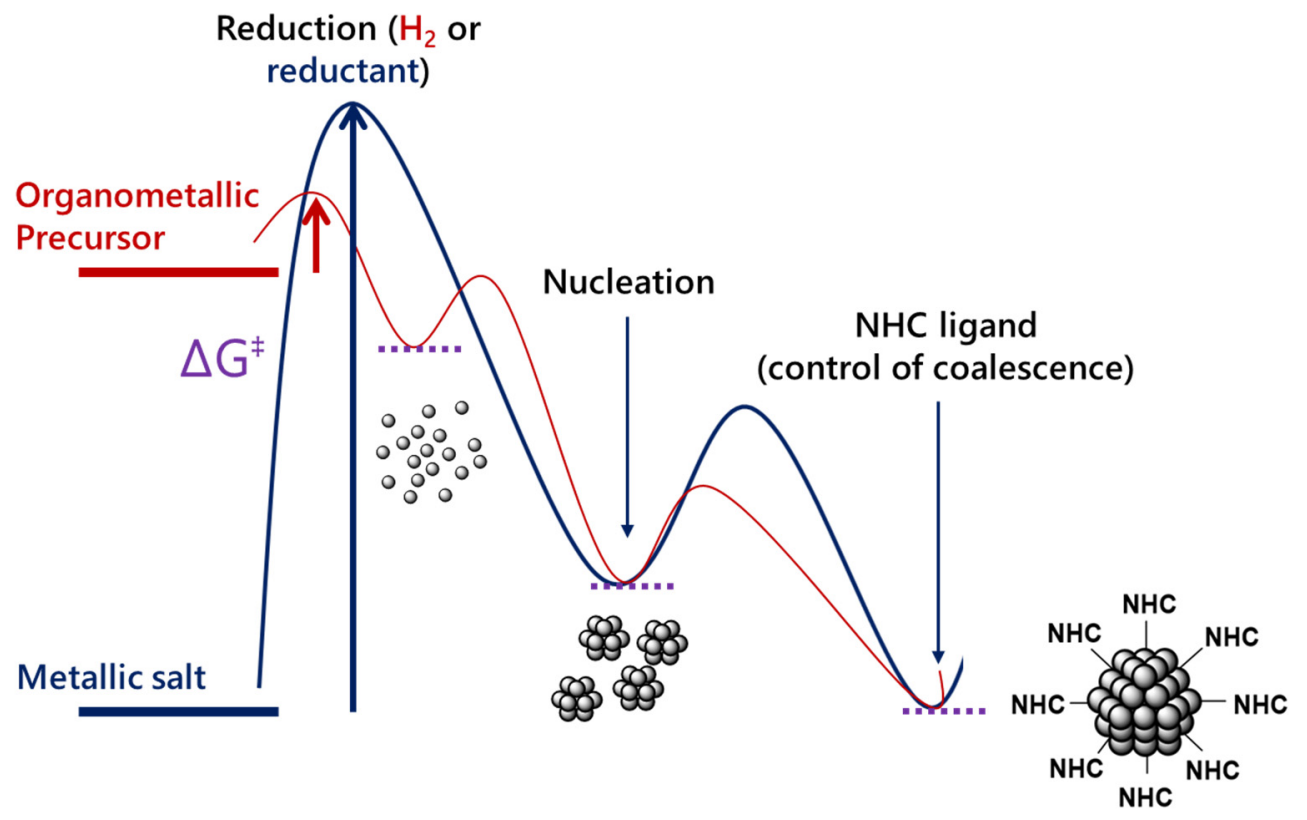

Figure 2. Formation of NHC-stabilized metallic nanoparticles (MNPs) starting from a high-energy organometallic precursor (red, organometallic approach) or a metallic salt (blue, conventional MNP synthesis).

Although during recent years the number of surface studies has proliferated, there is still a clear need for the development of fundamental studies of the coordination, location and dynamics of surface ligands on MNPs, as they influence their catalytic properties. In this respect, organometallic NPs ligated by NHCs have demonstrated to be suitable nano-objects for surface studies. Their clean surface, strong ligand-metal interaction and the possibility to control their catalytic properties through the stabilizing ligands make them perfect candidates for surface investigations. Traditionally, CO has been used as a probe molecule for the determination of location and dynamics of coordinated ligands on metal surfaces by magic-angle spinning solid-state NMR (MAS-NMR) and Fourier Transform Infrared (FT-IR). A pioneer infrared spectroscopy study of Bradley et al. about CO coordination on Pd NPs defined the coordination modes of $\mathrm{CO}$ on the MNP surface. While $\mathrm{CO}$ coordinates to the MNP faces in a bridging mode $\left(\mathrm{CO}_{\mathrm{b}}\right)$, it adopts a terminal mode $\left(\mathrm{CO}_{\mathrm{t}}\right)$ when adsorbs on the most exposed atoms of the surface (apexes and edges) [29]. A short time later, in collaboration with Chaudret, they demonstrated that the $\mathrm{CO}_{\mathrm{t}} / \mathrm{CO}_{\mathrm{b}}$ ratio depends on the particle size and increases when the MNP size decreases [30]. Therefore, through the coordination of $\mathrm{CO}$, the types of available active sites that exist at the MNP surface can be easily identified. Following these studies, in 2010, Novio et al. determined the location and dynamics 
of surface ligands by solid-state NMR [31], which also gives information about the coordination of the capping ligands on the metallic surface. Furthermore, X-ray photoelectron spectroscopy (XPS) has been recently presented as a promising tool to study the coordination modes of ancillary ligands on the MNP surface, apart from providing chemical information about the metallic surface atoms [32]. Therefore, FT-IR, XPS and solid-state MAS-NMR spectroscopy are established techniques for surface studies, which allow the identification of the surface active sites as well as the investigation of the coordination, location and dynamics of surface ligands on NHC-stabilized MNPs.

The aim of this review is to provide a general overview of organometallic NPs ligated by NHC ligands, focusing the study on the advantages of the use of molecular tools for their synthesis through an organometallic approach. The first part includes a revision of the three different methodologies, based on the organometallic approach, that are commonly employed for the synthesis of NHC-based NPs. The second part will deal with the surface studies of these nano-objects, enumerating the different spectroscopic techniques used and highlighting the relevance of $\mathrm{CO}$ adsorption for these studies. The last part of this review will focus on the effect of stabilizing NHC ligands related to the stability, solubility and catalytic activity of MNPs.

\section{Synthesis of NHC-Stabilized MNPs following the Organometallic Approach}

Since the early nineties, where in a collaborative effort between Bradley and Chaudret, $\mathrm{Ru}(\mathrm{COD})(\mathrm{COT})(\mathrm{COD}=$ cyclooctadiene; $\mathrm{COT}=$ cyclooctatriene $)$ was decomposed for the first time under a hydrogen stream to form Ru NPs [33], the reduction of high energy organometallic precursors as a clean and easy route for the formation of MNPs has been widely used as a synthetic method. This organometallic approach is based on the adequate selection of the precursor and the stabilizer that are going to be used. The organometallic precursors are usually zero- or low-valent metal complexes, which under mild conditions (e.g., 3 bar $\mathrm{H}_{2}$ and room temperature) easily decompose to form the corresponding nanoparticles (Figure 3). Normally, this decomposition occurs through the cleavage of the $\mathrm{M}-\mathrm{C}$ bond, which can be a sigma bond (alkyl, aryl or allyl), pi bond (olefins) or a combination of both [34]. In addition to these precursors, amides and nitrogen containing complexes have been also used for MNP synthesis through the organometallic approach (Figure 3). Each type of precursor presents a series of benefits and disadvantages. For example, olefinic complexes are especially appropriate since the unsaturated ligands are easily reduced under $\mathrm{H}_{2}$ toward the corresponding inert alkane, which does not interact with the MNP surface. On the other hand, amides or nitrogen-containing complexes can produce amines after their decomposition that coordinate on the particle surface and may modify the shape of the resulting MNPs. The decomposition rate of the organometallic precursors also plays an important role in the MNP synthesis, as it directs the nucleation and growth steps. When the decomposition rate is slow, the nucleation step is limited, and NPs are bigger than when the decomposition rate is fast. Therefore, organometallic NPs with different sizes and morphologies have been reported by using diverse organometallic precursors on this synthetic route, including colloidal systems of noble metal NPs ( $\mathrm{Ru}, \mathrm{Pt}, \mathrm{Pd})[27,28]$ or magnetic NPs of the first transition series $(\mathrm{Fe}, \mathrm{Co})[35,36]$.

Another key parameter to take into account in MNP synthesis is the stabilizer, which can be a polymer [37,38], ligand [39], ionic liquid (IL) [40], solvent [41] or even a solid support [42-44]. Apart from controlling the process of coalescence, the stabilizers are a cornerstone in MNP synthesis, since they govern their final size and morphology. Additionally, stabilizers can control the physical and chemical properties of MNPs and thus modulate their surface reactivity. Among all of them, ancillary ligands are excellent stabilizers for MNPs prepared by the organometallic approach, since, as already mentioned, they are able to transform the MNP surface properties. The formation of chemical bonds between the organic ligands and surface metal atoms results in a strong electronic stabilization, which leads to important modifications of the chemical reactivity of MNPs. In this context, NHCs have demonstrated to be a family of versatile stabilizing ligands that are able to modify the electronic or steric properties of MNPs by modifying their N-substituents or imidazolium structure [12-16,45]. 


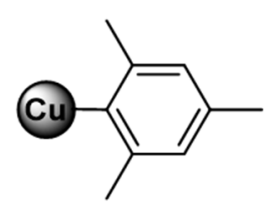

CuMes

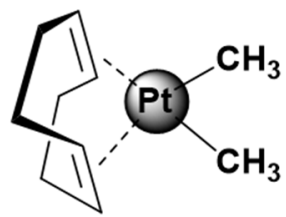

Pt(DME)(COD)
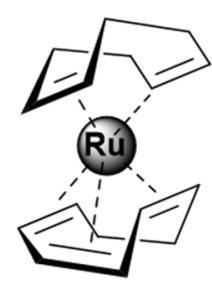

Ru(COD)(COT)

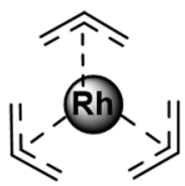

$\mathrm{Rh}($ allyl) 3<smiles>C[SiH2]N([SiH3])c1ccc(N([SiH3])[SiH2]C(C)(C)C)cc1</smiles>

$\left\{\mathrm{Fe}\left[\mathrm{N}-\left(\mathrm{SiMe}_{3}\right)_{2}\right]_{2}\right\}_{2}$

Figure 3. Example of organometallic precursors used in the organometallic approach for the preparation of MNPs. CuMes (Mes = mesitylene); $\mathrm{Ru}(\mathrm{COD})(\mathrm{COT})(\mathrm{COD}=$ cyclooctadiene; $\mathrm{COT}=$ cyclooctatriene); $\mathrm{Pt}(\mathrm{DME})(\mathrm{COD})(\mathrm{DME}=$ dimethyl $) ; \mathrm{Rh}(\text { allyl })_{3}\left(\right.$ allyl $\left.=\eta^{3}-\mathrm{C}_{3} \mathrm{H}_{5}\right) ;\left\{\mathrm{Fe}\left[\mathrm{N}-\left(\mathrm{SiMe}_{3}\right)_{2}\right]_{2}\right\}_{2}$.

The synthesis of NHC-stabilized organometallic NPs was first reported in 2011 by Lara et al., who used 1,3-bis(2,6-diisopropylphenyl)imidazol-2-ylidene (IPr) and N,N-di(tert-butyl)imidazol-2-ylidene (ItBu) for the stabilization of Ru NPs (Figure 4a) [12]. More specifically, these NHC-stabilized MNPs were obtained by reduction of $\mathrm{Ru}(\mathrm{COD})(\mathrm{COT})$ at room temperature under $3 \mathrm{bar} \mathrm{H}_{2}$ and in the presence of $\mathrm{I} t \mathrm{Bu}$ and $\mathrm{IPr}(0.2$ and 0.5 equivalents). Interesting differences in size, stability and catalytic activity were observed as a function of the amount of stabilizer used and the nature of the N-substituents. For example, in the case of the bulky It Bu, it was necessary to add 0.5 equiv. to stabilize Ru NPs, since when employing 0.2 equiv., a black precipitate was observed. Surface studies allowed the authors to observe that ItBu mostly coordinates to the more exposed surface atoms (apexes and edges), as the bulky $t \mathrm{Bu}$ groups prevent their coordination of the nanoparticle faces. On the other hand, stable Ru NPs were obtained by using either 0.2 or 0.5 equiv. of IPr. In this case, the higher the amount of stabilizer, the smaller the MNP size found. This behavior was previously observed on Ru NPs stabilized with other capping ligands such as alkylamines or alkylthiols [46]. The synthesis of Rh nanoparticles stabilized by NHC ligands was described a few years later by Godard et al. [47]. These nanoparticles were also prepared by the decomposition of the organometallic precursor $\mathrm{Rh}\left(\eta^{3}-\mathrm{C}_{3} \mathrm{H}_{5}\right)_{3}$ (Figure 3) in the presence of non-stoichiometric amounts of IPr ligand (from 0.2 to 0.6 equiv.). Small and monodisperse nanoparticles displaying mean sizes between c.a. 1.3 to $1.7 \mathrm{~nm}$ were obtained. Again, smaller mean diameters were detected as the ligand/metal ratio increased. The strong interaction between the NHC and the Rh surface was confirmed by ligand displacement experiments with high CO pressures, $\mathrm{PPh}_{3}$ and $\mathrm{P}(\mathrm{OPh})_{3}$. Additionally, they confirmed by solution and solid-state NMR the co-existence of IPr and the protonated carbene $\left(\operatorname{IPr} \mathrm{H}^{+}\right)$at the MNP surface. The catalytic activity of these colloids was studied in different reduction reactions (phenol derivatives and N-heteroaromatics), being active but highly sensitive to the size of the substrates.

The synthetic methodology employed in the previously mentioned works implies the isolation of the free NHC ligand in a preliminary step. However, most of NHC ligands are non-isolable due to the high reactivity of the carbenic carbon, thereby limiting the number of NHCs that could be used for MNP stabilization. With the intention to circumvent this limitation, Martínez-Prieto et al. developed a new approach to stabilize Ru NPs with non-isolable NHCs [20], which is centered on the in-situ formation of the free carbene. After the deprotonation of the imidazolium salt with $\mathrm{KO} t \mathrm{Bu}$ in solution, the corresponding non-isolable NHC ligand is transferred to the reactor containing the organometallic precursor by filtration through Celite. Then, the reaction mixture is pressurized with $\mathrm{H}_{2}$, 
forming the NHC-stabilized MNPs. The filtration step ensures the elimination of the inorganic salts formed in the deprotonation step that could coordinate to the surface nanoparticle, poisoning it, and blocking the active sites. Martínez-Prieto et al. validated the new methodology by the formation of Ru NPs ligated by 1,3-dicyclohexylimidazol-2-ylidene $(\mathrm{Ru} / \mathrm{ICy})$ by the comparison of the two synthetic routes: from (1) the free carbene ICy (original methodology, Scheme 1), and (2) by the in-situ deprotonation of the corresponding imidazolium salt, $\mathrm{ICy} \cdot \mathrm{HCl}$ (new methodology, Scheme 1). When comparing the two synthetic methods by Transmission Electron Microscopy (TEM), both showed a similar size and distribution (1.23 and $1.25 \mathrm{~nm}$ for the original and new methodology, respectively; see Scheme 1), thus establishing the new procedure for the formation of NHC-ligated MNPs. In sum, this new route circumvented the main limitation of the original method, where it was first necessary to isolate the free $\mathrm{NHC}$, avoiding any possible contamination on the metallic surface derived from the imidazolium salts and increasing the number of NHC ligands that could be used as stabilizers. In fact, following this new methodology, a great number of new NHC-stabilized organometallic NPs have been prepared, including various metals such as, $\mathrm{Ru}, \mathrm{Pt}, \mathrm{Ni}$ and $\mathrm{Ir}$, and numerous non-isolable NHCs with different structures and morphologies, such as chiral [20], long-chain [13,23] or hydrosoluble [48] NHCs (Figure 4).

1) Original methodology
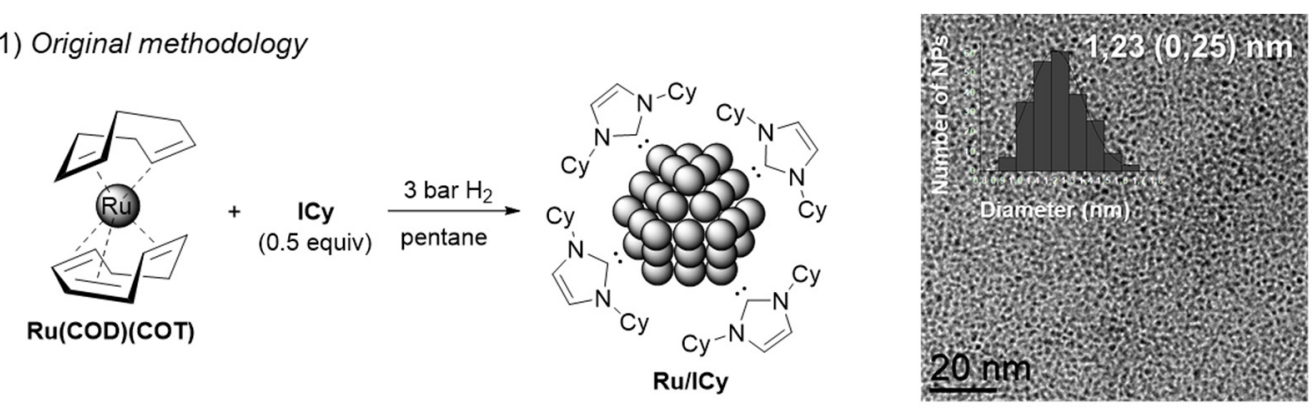

2) New methodology
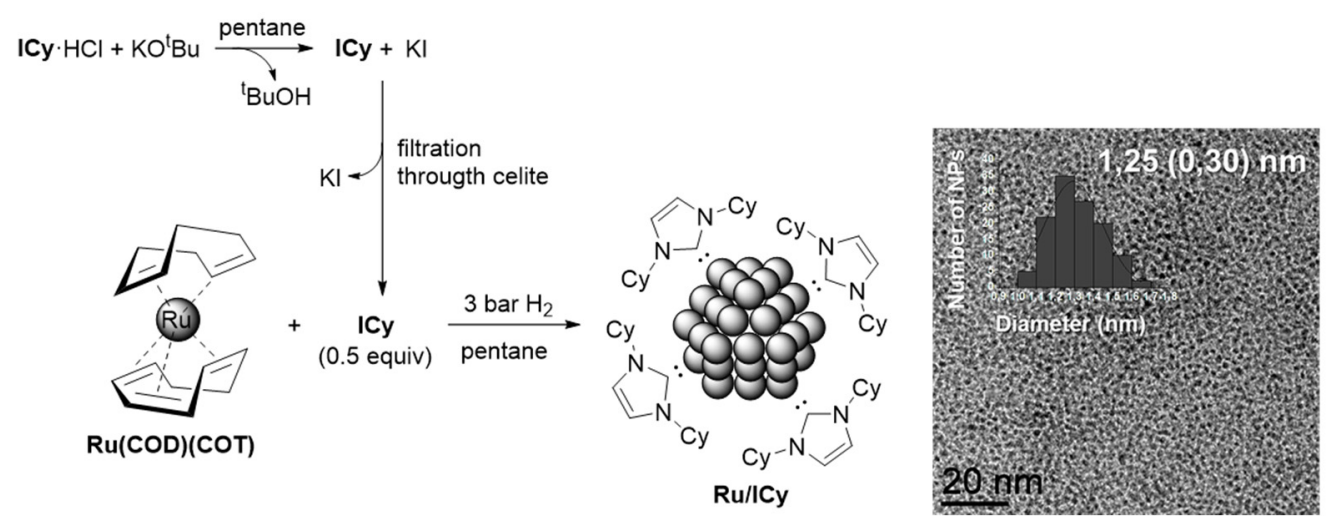

Scheme 1. Left: Synthesis of Ru/ICy following the (1) original and the (2) new methodology. Right: TEM micrographs of Ru/ICy. Adapted from reference 20. Copyright 2015 Wiley-VCH. 
a)<smiles></smiles>

ItBu

b)

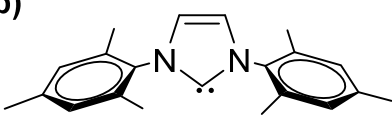

IMes

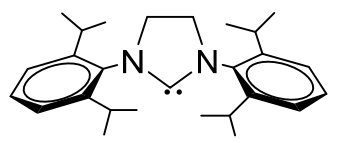

SIPr

c)

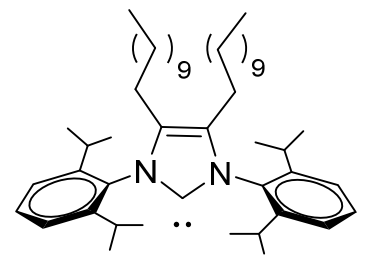

LC-IPr

d)

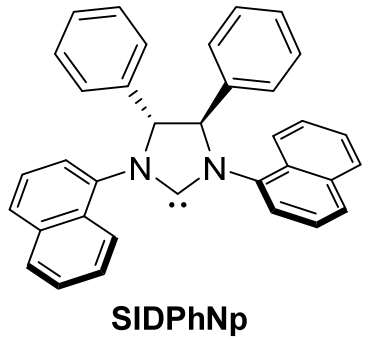

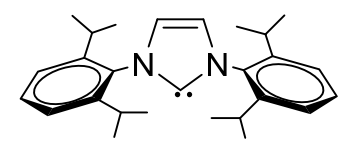

IPr<smiles>CC1=C(C)N(C(C)C)CN1C(C)C</smiles>

$\mathrm{IIPr}_{2} \mathrm{Me}_{2}$<smiles>CC(N1C=CN([C@@H](C)C(C)(C)C)C1)C(C)(C)C</smiles>

ItBuEt

\section{LC-IMe}<smiles>OC(c1ccccc1)[C@@H](c1ccccc1)N1CCN([C@H](c2ccccc2)[C@H](O)c2ccccc2)C1</smiles>

e)

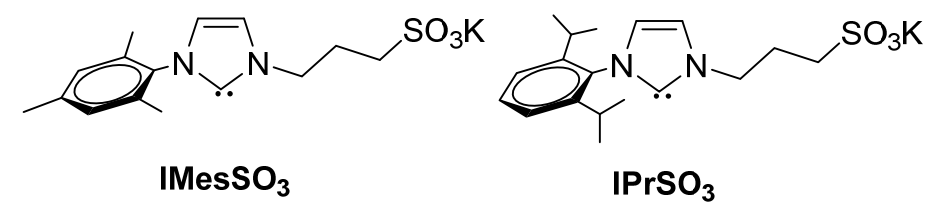

Figure 4. (a,b) Isolable NHCs used by Lara et al. in references 12 and 69. Non-isolable (c) long-chain, (d) chiral and (e) hydrosoluble NHCs used by Martínez-Prieto et al. in references 13, 23, 20 and 48.

A third methodology based in the decarboxylation of a zwitterionic $\mathrm{CO}_{2}$ adduct has been recently reported by Claver et al. [49]. Here, 1,3-dialkylimidazolium-2-carboxylate, of general formula $\mathrm{R}_{2} \mathrm{Im}-\mathrm{CO}_{2}$, was used as carbene precursor for the formation of NHC-stabilized organometallic NPs. More specifically, $\mathrm{Ni}(\mathrm{COD})_{2}$ was reduced under 3 bar $\mathrm{H}_{2}$ at $60^{\circ} \mathrm{C}$ in the presence of different amounts of $\mathrm{Me}_{2} \mathrm{Im}-\mathrm{CO}_{2}$ (0.1, 0.2, 0.5 and 1 equiv.) to afford small and well-defined NHC-stabilized Ni NPs (Figure 5). As previously observed by Lara et al. with $\mathrm{Ru} / \mathrm{It} \mathrm{Bu}$ [12], it was necessary to introduce at least 0.5 equiv. of $\mathrm{Me}_{2} \mathrm{Im}-\mathrm{CO}_{2}$ to obtain a colloidal suspension without agglomerations (Figure $5 \mathrm{~b}$ ). The direct decarboxylation of this imidazolium carboxylate avoids the previous isolation of the free carbene or any basic pretreatments. However, the number of $\mathrm{CO}_{2}$ adducts that can be used as carbene precursor, and it cannot be considered a general synthetic method. 
a)

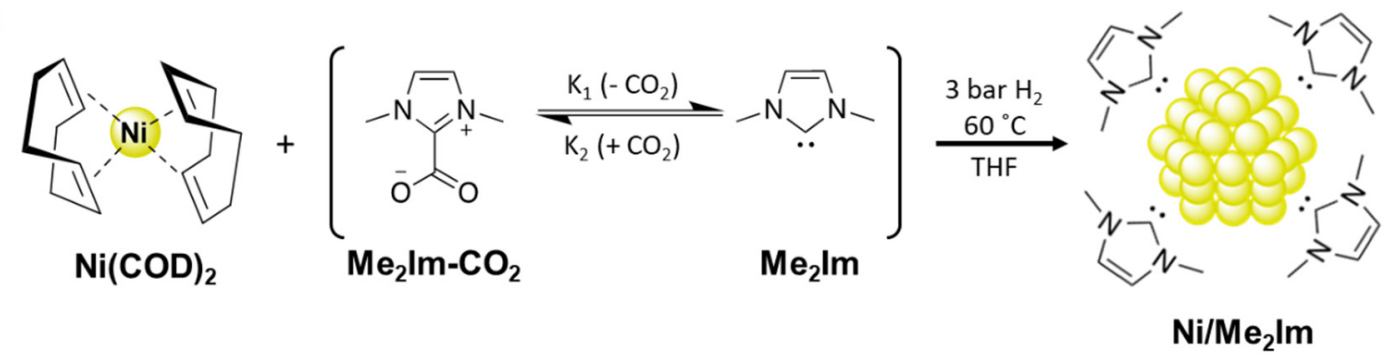

b)
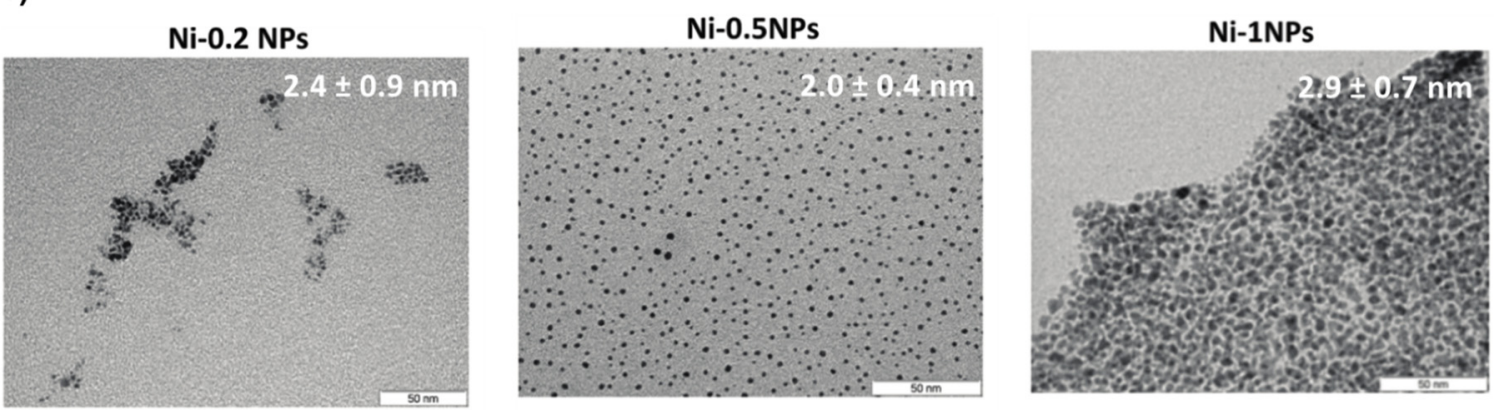

Figure 5. (a) Synthesis of $\mathrm{Ni} / \mathrm{Me}_{2} \mathrm{Im}$ as an example of NHC-based organometallic MNP from imidazolium carboxylate. (b) TEM images and size distribution of $\mathrm{Ni}_{0.2}, \mathrm{Ni}_{0.5}$ y Ni $\mathrm{Ni}_{1} / \mathrm{Me}_{2} \mathrm{Im} \mathrm{NPs}$. Adapted from reference 49. Copyright 2017 The Royal Society of Chemistry.

Although the organometallic approach has been proven to be a very convenient synthetic method for the synthesis of MNPs stabilized with NHC ligands, they can also be prepared by other synthetic methods (Scheme 2). Briefly, NHC-stabilized MNPs are mainly prepared by three different approaches: (i) by metallic precursor reduction in the presence of an NHC ligand, (ii) by ligand exchange of presynthesized MNPs and (iii) by direct decomposition of functionalized metal NHC complexes [50]. The synthesis of NHC-stabilized MNPs via ligand exchange consists of the displacement of surface ligands from nanoparticle surface by a better stabilizing ligand, which forms a stronger bond with the metal surface (Scheme 2ii). In this way, a surface modification that leads to a change in the physical or chemical properties of the NP in terms of solubility, stability or catalytic properties is achieved. The preparation of NHC-stabilized MNPs by ligand exchange has been widely employed since it was first reported by Fairlamb and Chechik [17]. Although they successfully displaced a thioether (dodecylsulfide) weakly bound from the MNP surface by the addition of ItBu, the resultant NHC-stabilized Au NPs presented a limited stability in solution, since gold leaching to form complexes or aggregates was observed. Following the same strategy (ligand exchange of thioether-coated MNPs) but using NHCs substituted with long alkyl chains (LC-NHCs), Ravoo and Glorius synthesized NHC-stabilized Pd NPs [51]. By comparing two ligands with different steric hindrance, namely LC-IMe and LC-IPr (Figure 4c), they observed that N-methyl substituents facilitate the ligand exchange, obtaining soluble and stable MNPs. However, with the sterically demanding LC-IPr, the same tendency of leaching already reported by Fairlamb and Chechik was observed, and the NHC-stabilized Pd NPs quickly aggregated in solution.

The direct decomposition of an NHC organometallic complex is a popular bottom-up synthetic method (Scheme 2iii), where the NHC-metal complex is reduced by a reducing agent (e.g., $\mathrm{NaBH}_{4}$ ) [52,53], or thermally decomposed to form NHC-stabilized MNPs. In the first case, the MNP size can be easily controlled by modifying the concentration of the metal precursor and the reducing agent [54]. In 2014, Baquero et al. reported the thermal decomposition of a sulfonated NHC-Pt complex in water, which leads to the formation of ultra-stable water-soluble Pt NPs $[55,56]$. Similar results were obtained by Asensio et al. with the analogous Pd hydrosoluble complexes $[57,58]$. 


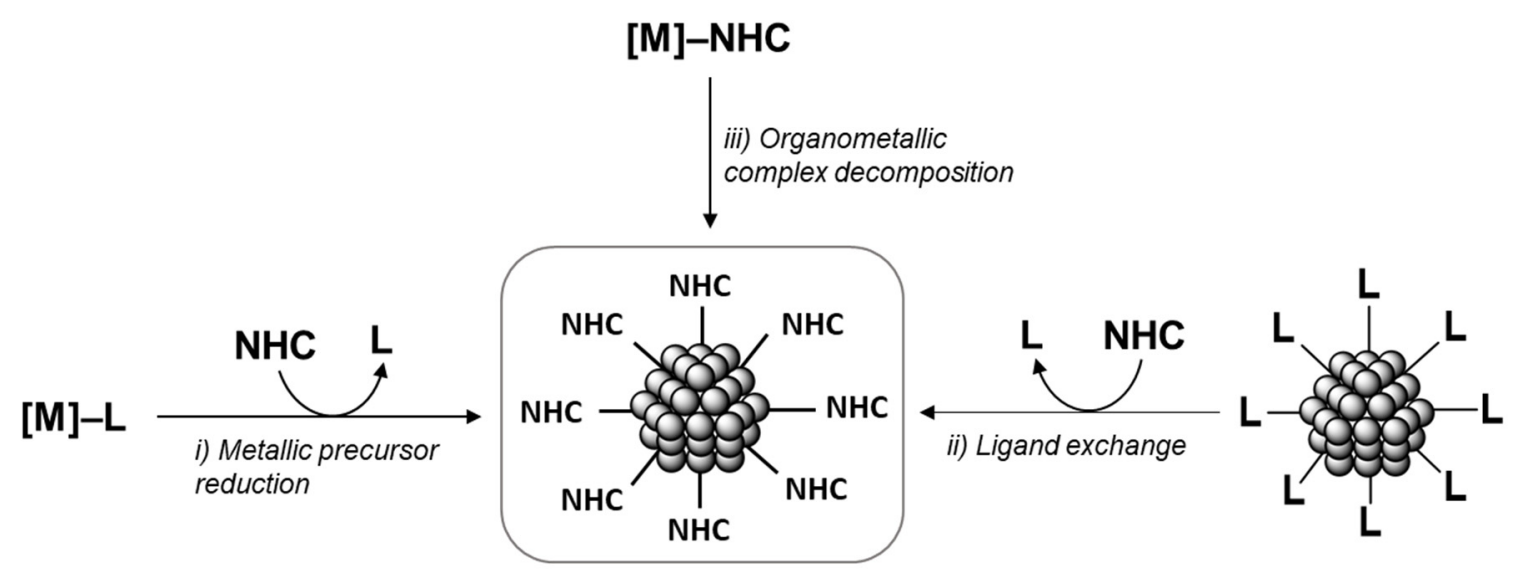

Scheme 2. Different synthesis methodologies for NHC-stabilized MNPs.

\section{Surface Studies}

As previously mentioned in the introduction, there is a strong need for a deeper understanding of the coordination mode, location and dynamics of surface ligands and the influence of such stabilizers in the chemical and physical properties of MNPs [59-63]. Bradley's group was one of the first to use spectroscopic techniques for the superficial characterization of highly dispersed colloids in solution [29]. More specifically, they performed infrared and NMR studies of carbon monoxide adsorption on transition metal colloids [64-67]. In this way, Bradley et al. established CO adsorption as a suitable technique to study MNP surfaces through the location of the active sites of MNPs. Moreover, through these surface studies it is possible to investigate the position and dynamics of surface ligands, as was later described by Novio et al. [31]. For this purpose, the authors examined the coordination of $\mathrm{CO}$ at the metallic surface of two sets of organometallic Ru NPs, stabilized either by a polymer (polyvinylpyrrolidone; PVP), Ru/PVP, or by an ancillary ligand (bisdiphenylphosphinobutane; dppb), $\mathrm{Ru} / \mathrm{dppb},[37,46]$ under mild conditions to avoid any superficial modification of the MNP. First, by combination of FT-IR and NMR spectroscopies, Novio et al. evidenced the coordination modes and dynamics of $\mathrm{CO}$ at the metal surface (Figure 6) - i. e., in a bridge mode $\left(\mathrm{CO}_{\mathrm{b}}\right)$ on the faces of the NPs or in a terminal mode $\left(\mathrm{CO}_{\mathrm{t}}\right)$ on the most exposed atoms (edges and apexes). MAS-NMR of Ru/PVP showed a great mobility of the $\mathrm{CO}$ adsorbed, since at short periods of $\mathrm{CO}$ exposure, there is mainly a broad signal centered at ca. $250 \mathrm{ppm}$ which corresponds to $\mathrm{CO}_{\mathrm{b}}$, while at longer exposure times, a sharp signal at ca. $200 \mathrm{ppm}\left(\mathrm{CO}_{\mathrm{t}}\right)$ appears at the cost of the broad one (Figure 7, left). On the other hand, MAS-NMR of $\mathrm{Ru} / \mathrm{dppb}$ revealed signals at ca. $240\left(\mathrm{CO}_{\mathrm{b}}\right)$ and $200 \mathrm{ppm}\left(\mathrm{CO}_{\mathrm{t}}\right)$ that did not show any displacement even at longer $\mathrm{CO}$ exposure times (Figure 7, right), which indicated the lack of mobility of $\mathrm{CO}$ on this MNP surface. Moreover, the cross-polarization (CP) NMR spectrum of Ru/dppb showed a decrease in the $\mathrm{CO}_{\mathrm{b}}$ signal compared to the terminal one, indicating that $\mathrm{CO}_{\mathrm{t}}$ was close to the dppb ligands, probably located on the apexes and edges. This work highlights the influence of surface ligands on the dynamics of adsorbed CO. While bulky ligands led to a slow-down fluxionality of adsorbed molecules, the absence of these permitted their mobility. 


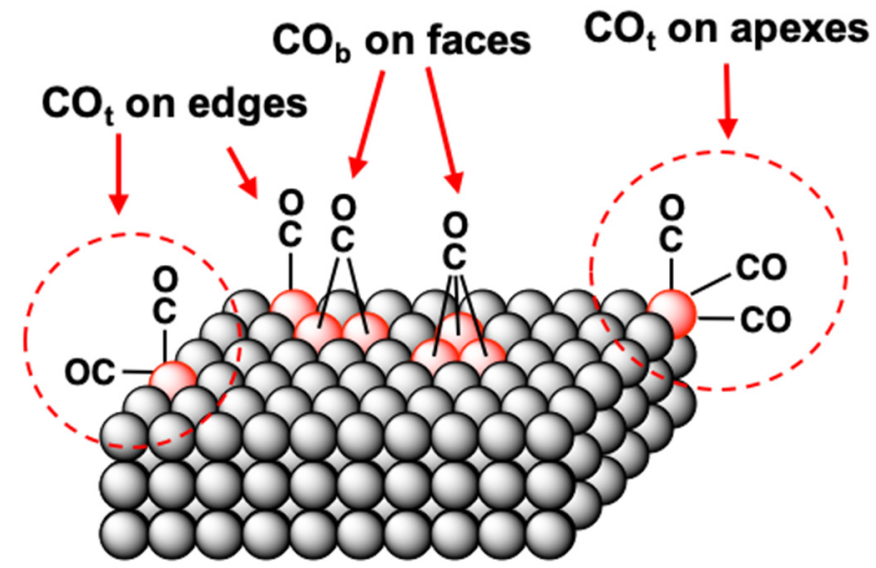

Figure 6. Coordination modes of CO to a metal surface. Adapted from reference 28. Copyright 2018 American Chemical Society.
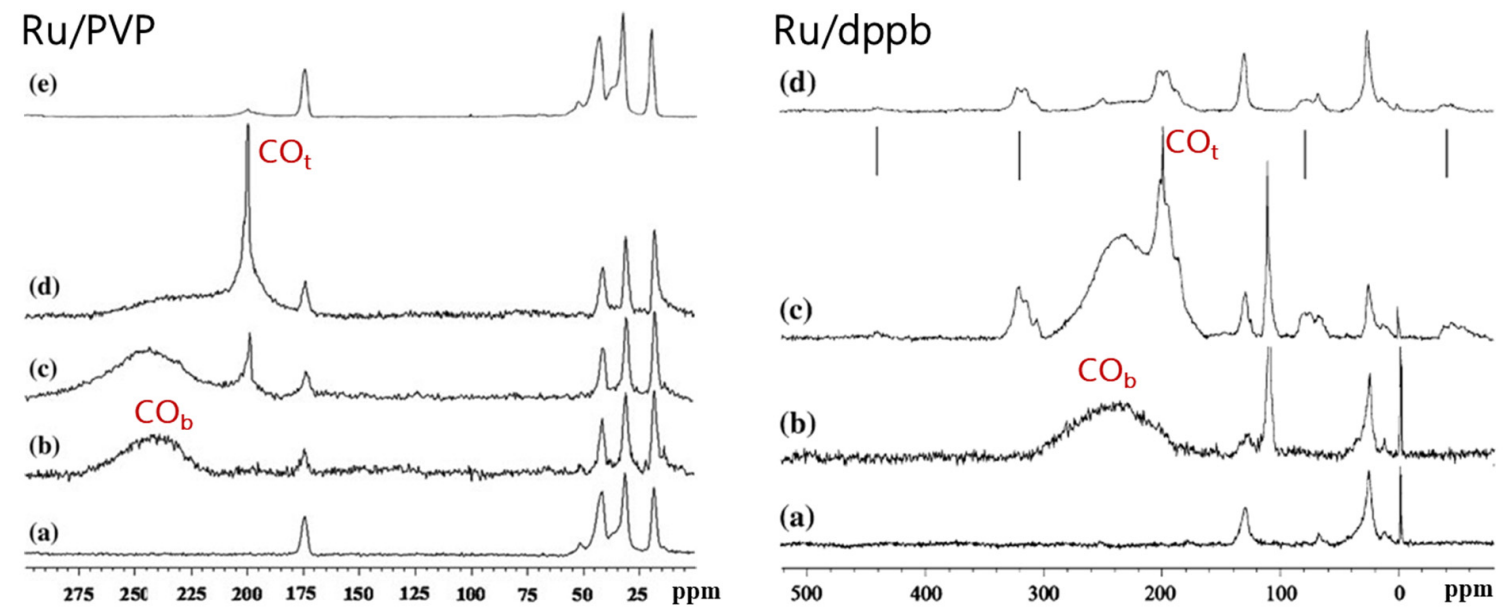

Figure 7. Left: ${ }^{13} \mathrm{C}$ MAS-NMR of Ru/PVP after exposure of 0.5 bar ${ }^{13} \mathrm{CO}$ at 0 (a), 2 (b), 6 (c) and $12 \mathrm{~h}$ (d).

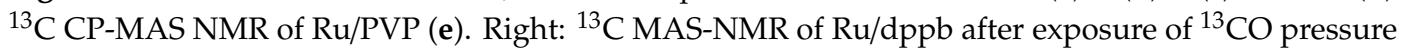

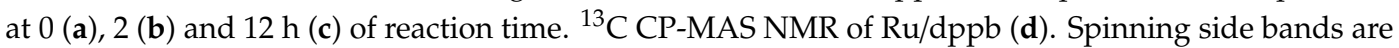
indicated below the spectrum. Extracted with permission of reference 31. Copyright 2010 Springer.

The use of $\mathrm{CO}$ as a probe molecule to determine the active sites and the dynamics of surface ligands is a useful tool to study the surface chemistry of ligand-stabilized MNPs by FT-IR [68,69]. In 2017, Martínez-Prieto et al. reported an infrared (FT-IR) surface study of Pt NPs ligated by long-chain NHC ligands (LC-IPr and LC-IMe; Figure 4c) [23]. After reaction with CO, FT-IR spectra of Pt/LC-NHCs showed the characteristic stretching bands of $\mathrm{CO}_{\mathrm{b}}$ (at $1820 \mathrm{~cm}^{-1}$ for Pt/LC-IPr and $1800 \mathrm{~cm}^{-1}$ for $\mathrm{Pt} / \mathrm{LC}-\mathrm{IMe}$ ) and $\mathrm{CO}_{\mathrm{t}}$ (at $2035 \mathrm{~cm}^{-1}$ for Pt/LC-IPr and $2030 \mathrm{~cm}^{-1}$ for Pt/LC-IMe) (Figure 8a). In both cases, terminal $\mathrm{CO}$ appeared as a strong band and bridging $\mathrm{CO}$ as a weak and broad one. Interestingly, the ratio $\mathrm{CO}_{t} / \mathrm{CO}_{\mathrm{b}}$ provides an idea about the percentage of available surface face sites present in MNPs, which is in close relation to the amount of ligand at the surface and the size of the nanoparticle. Normally, the higher the amount of stabilizing ligand, the smaller the size of the MNP and lower the amount of available faces. This correlation was also clearly observed by Martínez-Prieto et al. with Pt NPs stabilized with different numbers of equivalents of amidinate zwitterionic ligands (ICy. ${ }^{(p-t o l)} \mathrm{NCN}$, 1,3-dicyclohexylimidazolium-2-di-p-tolylcabodiimide) (Scheme 3) [70]. These novel betaine adducts were previously used as effective ligands for the stabilization of ultra-small Ru NPs (ca. $1 \mathrm{~nm}$ ) [71]. The FT-IR spectrum of Pt NPs stabilized with 0.1 equiv. of ICy. ${ }^{(p-t o l)} \mathrm{NCN}\left(\mathrm{Pt} / \mathrm{ICy} \cdot{ }^{(p-t o l)} \mathrm{NCN}_{0.1}\right)$ showed the characteristic $\mathrm{CO}_{\mathrm{b}}$ band at $1845 \mathrm{~cm}^{-1}$ and the $\mathrm{CO}_{\mathrm{t}}$ stretching frequency at $2038 \mathrm{~cm}^{-1}$ (Figure $8 \mathrm{~b}$, top). The FT-IR spectrum of Pt/ICy. ${ }^{(p-t o l)} \mathrm{NCN}_{0.2}$ exhibited similar $\mathrm{CO}$ bands, but with a higher $\mathrm{CO}_{\mathrm{t}} / \mathrm{CO}_{\mathrm{b}}$ 
ratio (Figure $8 b$, centre). This trend continued for $\mathrm{Pt} / \mathrm{ICy} \cdot\left({ }^{(p-t o l)} \mathrm{NCN}_{0.5}\right.$, displaying the highest $\mathrm{CO}_{\mathrm{t}} / \mathrm{CO}_{\mathrm{b}}$ ratio of all the samples studied in this work (Figure 8b, bottom). Here, it can be clearly observed how by enlarging the amount of ligand at the metal surface, the intensities of $\mathrm{CO}_{\mathrm{t}}$ band increase at the expense of $\mathrm{CO}_{\mathrm{b}}$, indicating that $\mathrm{Pt} / \mathrm{ICy} \cdot{ }^{(p-t o l)} \mathrm{NCN}_{0.1}$ has more available face sites than $\mathrm{Pt} / \mathrm{ICy} \cdot{ }^{(p-t o l)} \mathrm{NCN}_{0.5}$.

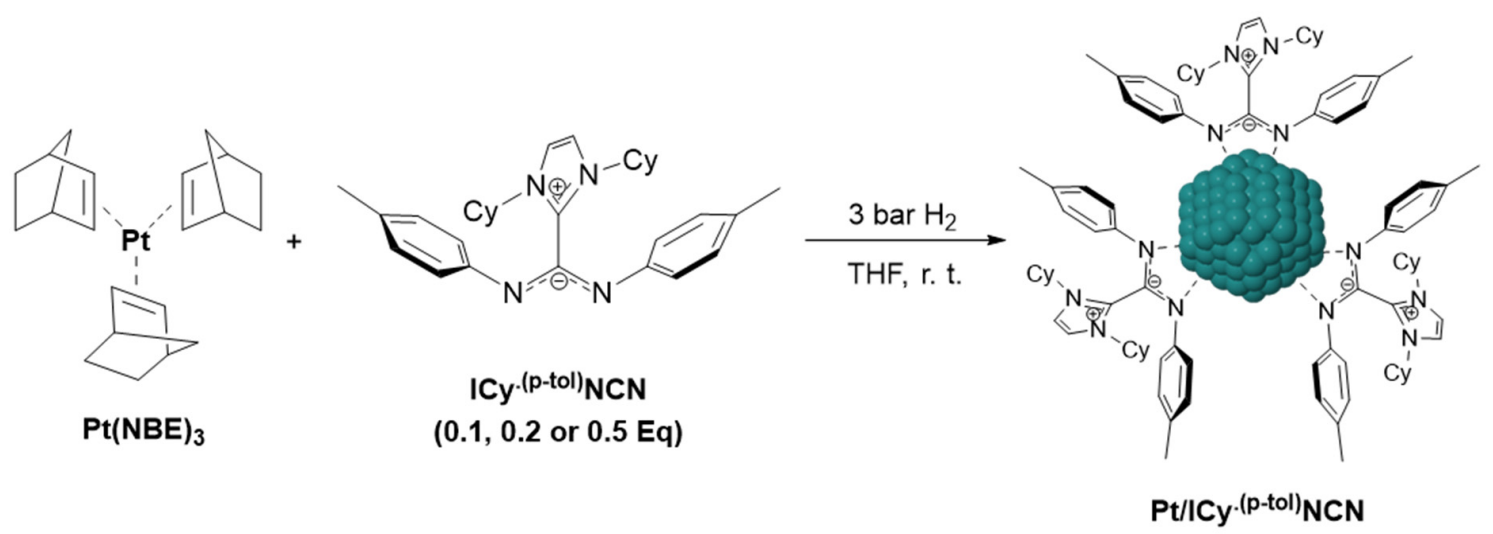

Scheme 3. Synthesis of Pt/ICy. ${ }^{(p-t o l)} \mathrm{NCN}$ with different amounts of imidazolium-amidinate ligands.

a)

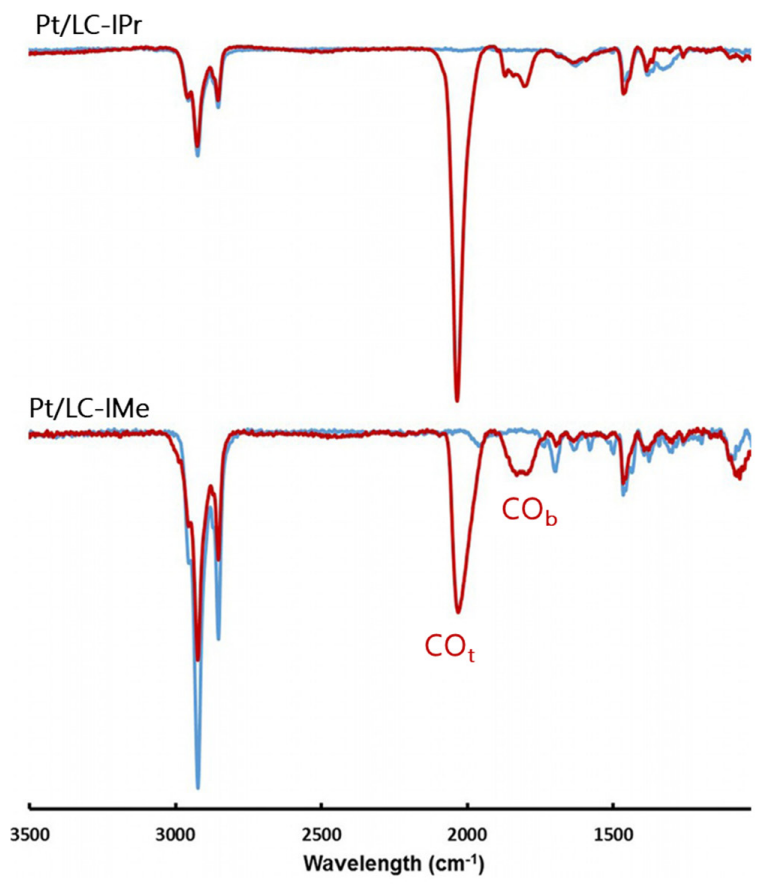

b)
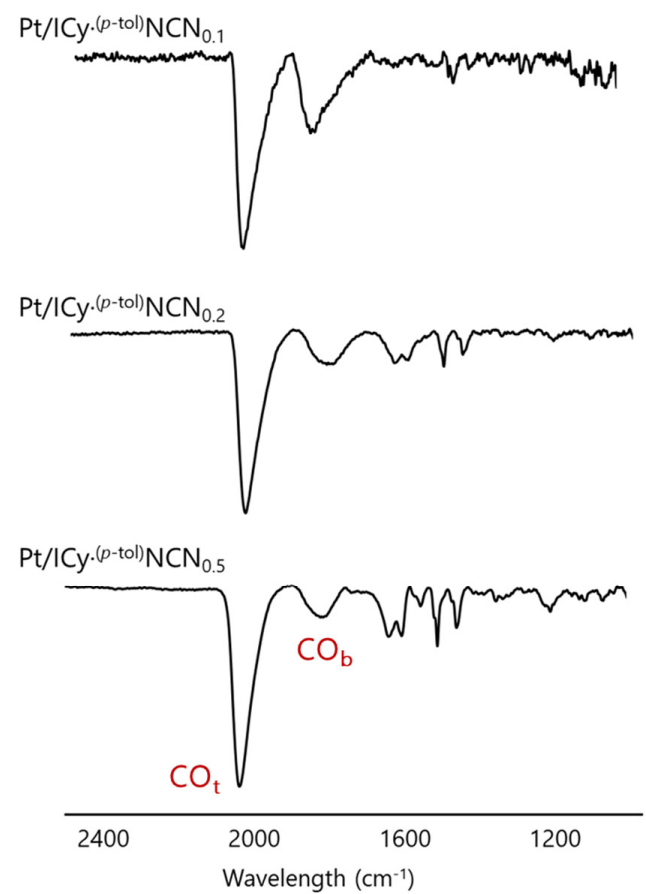

Figure 8. (a) FT-IR spectra of Pt/LC-IPr (top) and Pt/LC-IMe (bottom) before (blue) and after (red) CO exposure. Adapted from reference 23 with permission Wiley-VCH. b) FT-IR spectra of Pt NPs stabilized with 0.1 (a), 0.2 (b) and 0.5 equivalents of ICy. $\left(\mathrm{p}^{-\mathrm{tol})} \mathrm{NCN}\right.$. Adapted from reference 70. Copyright 2017 The Royal Society of Chemistry.

MAS-NMR is also a suitable technique to examine the surface state of NHC-stabilized MNPs through the coordination of $\mathrm{CO}$. In a didactic example, Martínez-Prieto et al. easily determined the location of the active sites of Ru NPs stabilized with LC-NHC ligands (LC-IPr and LC-IMe; Figure 4c) by MAS-NMR [13]. The ${ }^{13}$ C-MAS-NMR spectra of both colloids showed the characteristic signals of $\mathrm{CO}_{\mathrm{b}}$ (broad peak at ca. $230 \mathrm{ppm}$ ) and $\mathrm{CO}_{\mathrm{t}}$ (sharp peak at ca. $198 \mathrm{ppm}$ ). As can be seen in Figure 9, the $\mathrm{CO}_{\mathrm{b}}$ signal for $\mathrm{Ru} / \mathrm{LC}$-IMe is much less intense than for $\mathrm{Ru} / \mathrm{LC}-\mathrm{IPr}$, indicating that the latter has 
more available faces sites than $\mathrm{Ru} / \mathrm{LC}$-IMe as a consequence of the bulkiness of LC-IPr. In ${ }^{13} \mathrm{C} \mathrm{CP}$ MAS-NMR spectra of both nanosystems, the $\mathrm{CO}_{\mathrm{b}}$ signal disappears, and the intensity of the $\mathrm{CO}_{\mathrm{t}}$ one decreases, suggesting that bridging $\mathrm{CO}$ molecules are not in the proximity of the ligands, while terminal carbon monoxides partially are. This fact indicates that the NHC ligands preferably coordinate to the most exposed Ru atoms, which are those located on edges and apexes. The different surface states depending on the ligand used as stabilizer ( $\mathrm{Ru} / \mathrm{LC}$-IPr has more available faces than $\mathrm{Ru} / \mathrm{LC}$-IMe) is clearly reflected in a different catalytic behaviour, as will be later discussed in Section 4 (vide infra). Similar results were found by Lara et al. with Ru NPs stabilized with IPr and ItBu (Figure 4a) [12]. After exposure to ${ }^{13} \mathrm{CO},{ }^{13} \mathrm{C}$ MAS-NMR spectra of both $\mathrm{Ru} / \mathrm{I} t \mathrm{Bu}_{0.5}$ and $\mathrm{Ru} / \mathrm{IPr}_{0.2}$ presented a broad signal at ca. $240 \mathrm{ppm}$ corresponding to $\mathrm{CO}_{\mathrm{b}}$ and a sharp one at ca. $200 \mathrm{ppm}$ attributed to $\mathrm{CO}_{\mathrm{t}}$. However, the $\mathrm{Ru} / \mathrm{IPr}_{0.5}$ spectrum only showed the signal corresponding to $\mathrm{CO}_{\mathrm{t}}$, suggesting that the high amount of IPr blocks the MNP faces necessary for the coordination of $\mathrm{CO}$ in a bridging fashion.

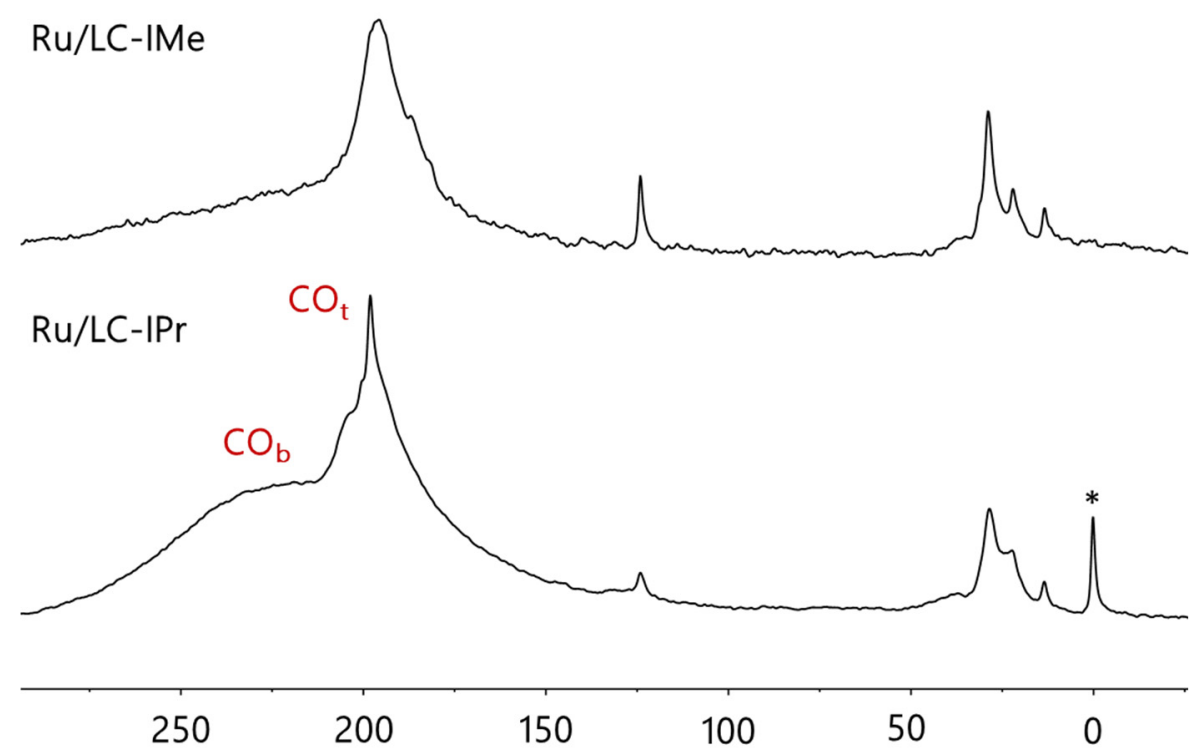

Figure 9. ${ }^{13} \mathrm{C}$-MAS NMR spectra of Ru/LC-IMe (top) and $\mathrm{Ru} / \mathrm{LC}-\mathrm{IPr}$ (bottom) after exposure to ${ }^{13} \mathrm{CO}$ (1 bar, 20h, r.t.). The peak with asterisk corresponds to grease. Extracted with permission from reference 13. Copyright 2016 The Royal Society of Chemistry.

NMR spectroscopy has been also successfully employed for the study of the coordination of the ligands to the MNP surface. In the already mentioned work reported by Lara et al., authors confirmed by liquid and solid-state NMR the presence of NHC ligands on the surface of Ru NPs [12]. In ${ }^{1} \mathrm{H}-\mathrm{NMR}$ spectra of $\mathrm{Ru} / \mathrm{It} \mathrm{Bu}_{0.5}$ and $\mathrm{Ru} / \mathrm{IPr}_{0.2-0.5}$, the signals of the $\mathrm{CH}$ groups of the imidazole backbones and the phenyl groups of IPr were not observed due to their proximity to the nanoparticle surface. This lack of signals is characteristic of the chemical bonding of the ligands to the MNP surface, and it is the result of a series of phenomena: i) an increased rigidity of the surface ligands, ii) a slow tumbling of the NP in solution and iii) surface heterogeneity [72,73]. The coordination of the ligands was also investigated by solid-state NMR by using ${ }^{13} \mathrm{C}$-labeled NHCs. The signal corresponding to the carbene carbon (between 190-205 ppm) was identified in all the labeled systems $\left(\mathrm{Ru} / \mathrm{It} \mathrm{Bu}_{0.5}{ }^{*}, \mathrm{Ru} / \mathrm{IPr}_{0.2}{ }^{*}\right.$ and $\left.\mathrm{Ru} / \mathrm{IPr}_{0.5}{ }^{*}\right)$ by ${ }^{13} \mathrm{C}$ MAS-NMR. The chemical shift found for the carbene atom at the surface of the particle was clearly different from that of the free carbene, thus demonstrating the coordination of the ligand to the Ru surface. In 2014, Baquero et al. also confirmed the coordination of an NHC-derived ligand to the surface of a platinum nanoparticle by solid-state NMR [55]. The water-soluble NHC-stabilized Pt NPs obtained by thermal decomposition of the corresponding ${ }^{13} \mathrm{C}$-labeled molecular complex [74-76] were studied by MAS-NMR. The ${ }^{13} \mathrm{C}$ CP MAS-NMR spectrum of the sulfonated NHC-stabilized Pt NPs showed a clear signal at ca. $177 \mathrm{ppm}$, attributed to the carbene carbon (Figure 10b). The determination 
for the first time of the ${ }^{13} \mathrm{C}-{ }^{195} \mathrm{Pt}$ coupling constant $(940 \pm 20 \mathrm{~Hz})$ between a ligand and a nanoparticle, confirmed the coordination of the NHC ligand to the nanoparticle surface. There, the coordination of the carbenic carbon to the $\mathrm{Pt}$ atom was weaker in comparison with that found in NHC-Pt(0) complexes (ca. $1365 \mathrm{~Hz}$ ) [77], but strongly more coupled than in the $\mathrm{Pt}(\mathrm{II})$ precursor (ca. $767 \mathrm{~Hz}$ ), where the oxidation state of the $\mathrm{Pt}(+2)$ decreased the coupling degree (Figure 10a). The observation of this coupling by MAS-NMR is clear evidence of the coordination of a carbene ligand with an MNP surface.

a)<smiles>CN1C=CN(CCCS(C)(=O)=O)C1P(C)(C)=O</smiles>

b)

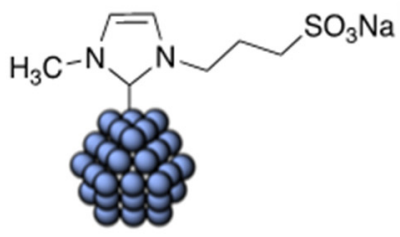

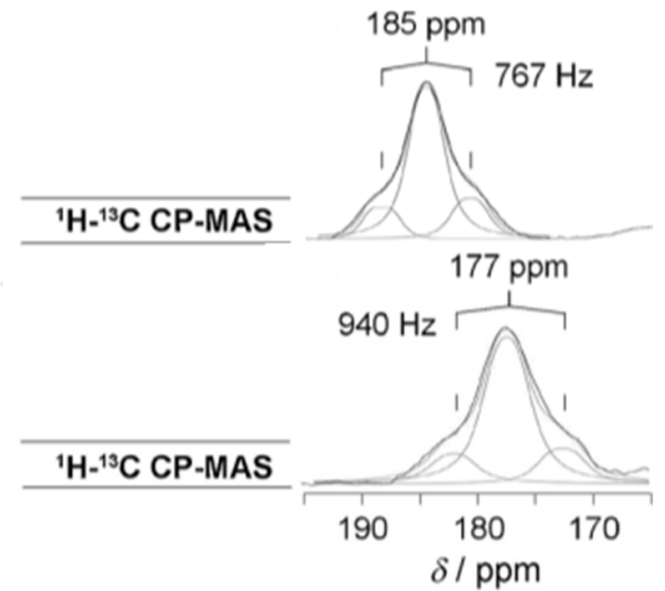

Figure 10. ${ }^{13} \mathrm{C}\left\{{ }^{1} \mathrm{H}\right]$ CP MAS-NMR spectra of (a) molecular Pt(II) complex and (b) NHC-stabilized $\mathrm{Pt}$ NPs. Reproduced from reference 55 with permission of Wiley-VCH.

The coordination of the NHC ligand on Pd NPs was also proved by the observation of Knight shift in the carbenic carbon by Asensio et al. [57]. Knight shift is the broadening and displacement of the NMR frequency of surface-adsorbed molecules because of the presence of free electrons on the surface of large MNPs [78,79]. In this study, ${ }^{13} \mathrm{C} C \mathrm{CPMG}$ echo MAS-NMR spectrum of Pd NPs stabilized with water-soluble ${ }^{13} \mathrm{C}$-labeled NHCs of $3.7 \mathrm{~nm}$ showed a Knight-shifted resonance of the carbenic carbon at ca. $600 \mathrm{ppm}$, which was an unambiguous indication of the direct coordination of the carbenic carbon to the metal surface. In addition, a correlation between the Pd NP size and the Knight shift of the ${ }^{13} \mathrm{C}$ NMR displacements of adsorbed CO molecules was stablished. For small Pd NPs (ca. $1.4 \mathrm{~nm}$ ), they observed the typical diamagnetic displacements (from 150 to $250 \mathrm{ppm}$ ); however, for larger NPs, the resonance of CO adsorbed was Knight shifted to ca. 750-800 ppm (Figure 11a). Similar nanoparticle size-dependence with the degree of the Knight shift observed was reported by Martínez-Prieto et al. [70]. Here, as well as in the previous example, small differences in the diameter of Pt NPs caused a displacement in the Knight-shifted signal of the adsorbed ${ }^{13} \mathrm{CO}$ molecules. After exposing Pt NPs stabilized with 0.1 equiv. $\left(\mathrm{Pt} / \mathrm{ICy} \cdot{ }^{(p-t o l)} \mathrm{NCN}_{0.1}\right)$ of $2.3 \mathrm{~nm}$ with ${ }^{13} \mathrm{CO}$, the ${ }^{13} \mathrm{C}$ MAS-NMR spectrum exhibited a broad and shifted CO peak at $400 \mathrm{ppm}$, while the spectra of $\mathrm{Pt}$ NPs of 2.1 and $1.9 \mathrm{~nm}$ showed the CO signals at 390 and 360, respectively. Therefore, as the size of the particles decreased, the CO signal was shifted to a lower frequency, being almost suppressed when the size was ca. $1.2 \mathrm{~nm}$ (Figure 11b), as previously observed in analogous smaller Pt $[80,81]$ and RuPt [82] systems. 

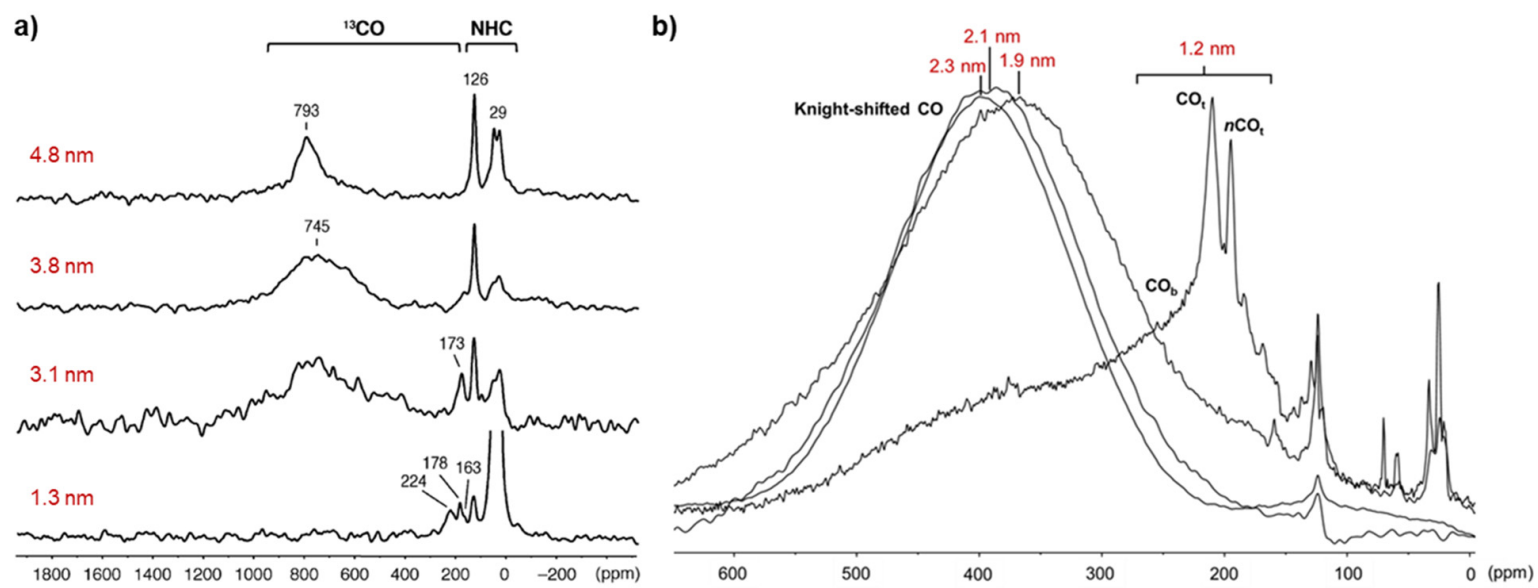

Figure 11. ${ }^{13} \mathrm{C}$ MAS-NMR spectra of (a) Pd and (b) Pt NPs with different sizes after exposure to ${ }^{13} \mathrm{CO}$. Extracted from reference 57 and 70 with permission of Wiley-VCH and The Royal Society of Chemistry, respectively.

In addition to solid-state NMR, XPS is a useful tool to investigate the coordination of ancillary ligands to the surface of MNPs. In 2016, the group of Glorius employed XPS for the first time to determine the coordination mode of bidentate NHC-thioether ligands on Pd NPs [32]. Through a comparative XPS study between the $\mathrm{N}$ 1s signals of the imidazolium salts ( $\mathrm{HBr} \cdot \mathrm{NHC}$-thioether) and the NHC-thioether stabilized Pd NPs, the authors established that the NHC is the coordinative species. The $\mathrm{N}$ 1s area of the Pd NPs presented a binding energy (BE) of 400.7-401.2 eV, which were the expected values for NHCs on metal surfaces [83,84]. On the other hand, the imidazolium salts used as ligand precursors showed a N 1s signal at higher BE (401.6-401.8 eV), because the electrons are strongly bound in these positive charged molecules (Figure 12a). The coordination of the carbene molecule was confirmed by analyzing the $\mathrm{N} 1 \mathrm{~s}$ signals of three different ICy species, the imidazolium salt (HCl-ICy), the free carbene (ICy) and the corresponding metal complex (ICy-Pd-Cl) (Figure 12b). ICy $\cdot \mathrm{HCl}$ exhibits the highest $\mathrm{BE}(401.5 \mathrm{eV})$ due to its cationic nature. The free carbene presents two peaks at 401.5 and $399.5 \mathrm{eV}$. The peak at $401.5 \mathrm{eV}$ corresponds to the protonated carbene during the preparation of the sample, and the signal at $399.5 \mathrm{eV}$ is attributed to the neutral free carbene. Lastly, the $\mathrm{Pd}$ complex, ICy-Pd-Cl, shows a peak at $400.5 \mathrm{eV}$, due to the loss of electron density in the $\mathrm{N}$ atoms after the coordination of the free NHC to the metal surface.

Shortly after, Martínez-Prieto et al. also used XPS to study the binding mode of NHC ligands on the nanoparticle surface. First, they confirmed the presence of water soluble NHCs (Figure 4e) on the ruthenium nanoparticle surface [48]. The $\mathrm{N} 1$ s signals for the WS-NHCs stabilized Ru NPs $\left(\mathrm{Ru} / \mathrm{IPrSO}_{3}\right.$ and $\mathrm{Ru} / \mathrm{IMesSO}_{3}$ ) showed lower binding energy values (399.5-400.2 eV) than their corresponding imidazolium salts (400.9-401.2 eV), demonstrating the direct coordination of these hydrosoluble ligands to the metallic surface (Figure 13). In addition, the same year and the same authors also employed XPS to investigate the coordination of long-chain NHCs (LC-IPr and LC-IMe; Figure 4c) in Pt NPs [23]. In line with previous observations, the N 1s signals for the Pt NPs displayed lower BEs (400.2-400.5 eV) than those for the protonated NHCs $(401.2-401.5 \mathrm{eV})$. These studies allowed establishing XPS as a suitable tool to identify the coordination of NHC ligands to the MNP surface, without the need of the preparation of labeled compounds $\left({ }^{13} \mathrm{C}\right)$ just like in NMR spectroscopy. 
a)
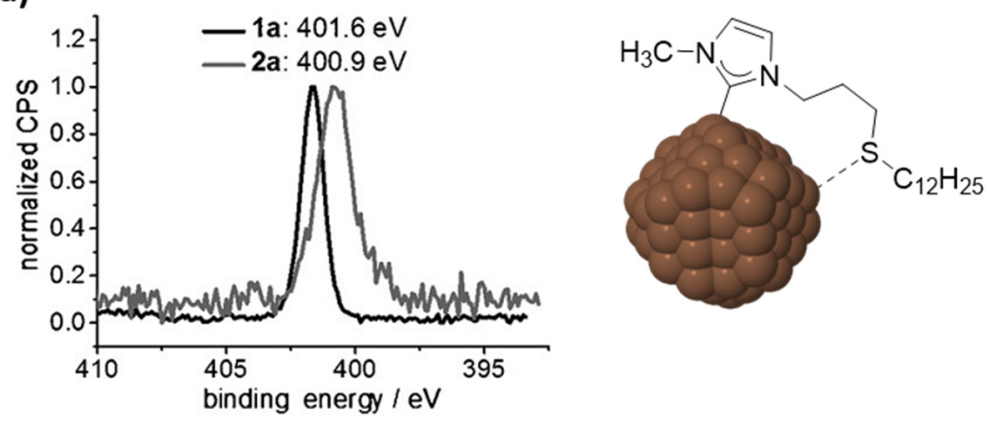

b)
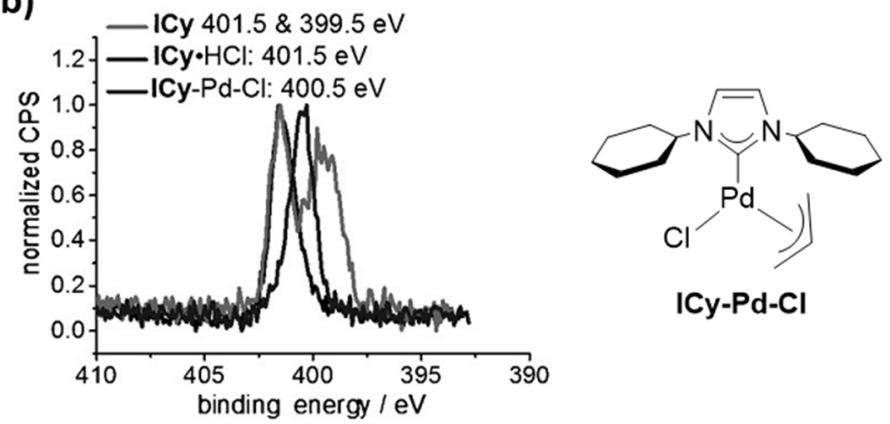

Figure 12. (a) Example of XPS for the N 1s signal of a Pd NP and its corresponding imidazolium salt. (b) Comparative study of free carbene ICy, HCl-ICy and Pd-ICy complex. Adapted from reference 32 with permission of Willey-VCH.
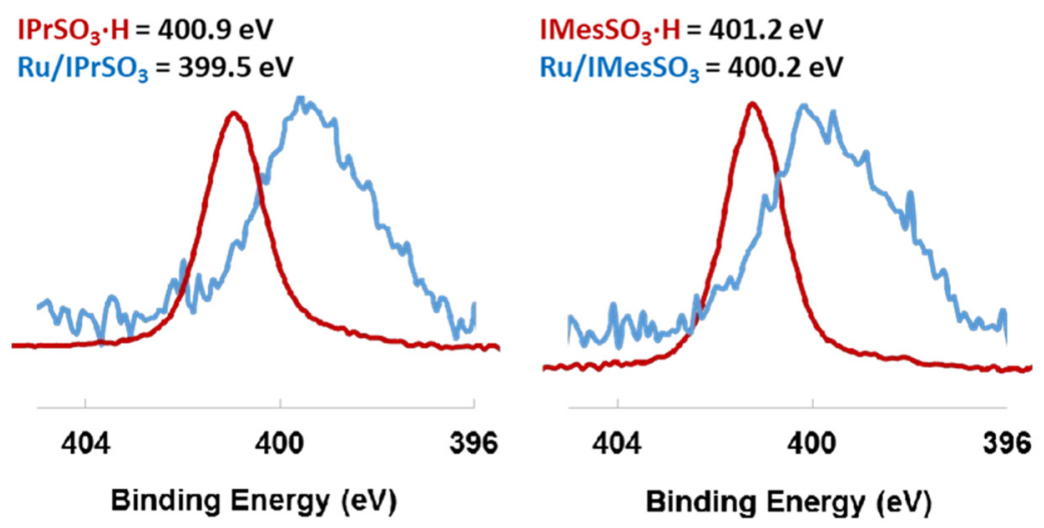

Figure 13. XPS of the $\mathrm{N}$ 1s signals of $\mathrm{Ru} / \mathrm{IPrSO}_{3}$ (blue, (left)), $\mathrm{Ru} / \mathrm{IMesSO}_{3}$ (blue, (right)) and their corresponding salts $\mathrm{IPrSO}_{3} \cdot \mathrm{H}$ (red, (left)) and $\mathrm{IMesSO}_{3} \cdot \mathrm{H}$ (red, (right)). Extracted with permission of reference 48. Copyright 2017 The Royal Society of Chemistry.

\section{Influence of NHCs in MNP Properties}

As previously pointed out in the introduction, the chemical and physical properties of MNPs can be modified depending on the stabilizing ligand used during the synthesis process or in a subsequent functionalization step, via ligand-exchange. In this context, NHCs are presented as versatile ligands which can easily modulate the MNP properties such as size, solubility, stability, surface state or catalytic activity. Therefore, the amount or nature of the NHC employed as a stabilizer will govern the catalytic properties of MNPs. 


\subsection{Controlling the Solubility and Stability}

One of the major challenges in nanoparticle chemistry is the synthesis of resistant NPs for their later use in catalytic applications, since most of them tend to agglomerate after the catalytic process as a result of their limited stability under reaction conditions, with the consequent loss of their catalytic properties [85]. Usually non-polar NHC-stabilized MNPs are soluble in organic solvents but present stability problems-e.g., $\mathrm{Au} / \mathrm{I} t \mathrm{Bu} \mathrm{NPs}$ rapidly aggregate in $\mathrm{DMSO}, \mathrm{CH}_{3} \mathrm{CN}$ or $\mathrm{CH}_{2} \mathrm{Cl}_{2}$ [17]. However, LC-NHC ligands confer a great stability and solubility to MNPs in organic solvents because of the long aliphatic chains located in the imidazole backbone (Figure 4c) [86]. In 2014, Ravoo in collaboration with Glorius used these long chain ligands for the first time to stabilize Pd NPs, creating a protective monolayer that prevents MNP aggregation [51]. In their work, they proved the importance of the $\mathrm{N}$-substituent of the imidazole group in the stabilization of Pd NPs, where, in order to minimize the steric repulsion between the NHC and the MNP surface, the N-substituents should be as small and flexible as possible (Figure 14a). Another clear example of the importance of the nature of the $\mathrm{N}$-substituents was reported by Bakker et al., whose work investigated the influence of the alkyl side groups on the coordination mode of NHCs in Au metal surfaces [87]. In short, they distinguished two different coordination modes depending on the length of the alkyl chain by combined DFT calculations, STM (Scanning Tunneling Microscopy) and XPS analyses. IBu with long alkyl chain coordinates in a Down $n_{\text {surf }}$ configuration and then remains in a flat-lying IBu-Au-IBu complex $\left(\right.$ Down $\left._{\mathrm{ad}}\right)$. In contrast, the carbene with a short alkyl chain (IMe) prefers to coordinate in an up-standing configuration with an $\mathrm{Au}$ adatom ( $\mathrm{Up}_{\mathrm{ad}}$; Figure 14b). However, other studies in this respect point to different coordination modes depending on the bulkiness of the N-bound organic substituents. NHCs bearing bulky N-substituents bind metallic surfaces ( $\mathrm{Au}, \mathrm{Ag}$ or $\mathrm{Cu}$ ) in a monocoordinated $\mathrm{Up}_{\mathrm{ad}}$, while NHCs with small $\mathrm{N}$-substituents adopt a bis-coordinated Down $\mathrm{ad}_{\mathrm{d}}$ binding mode [88].

a)

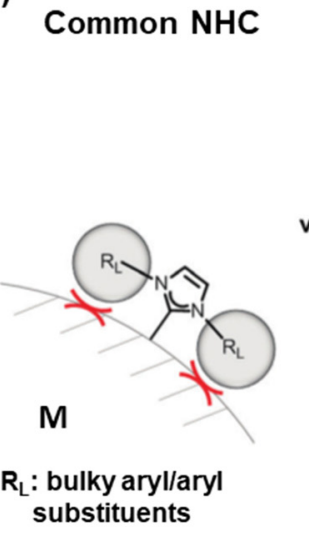

LC-NHC

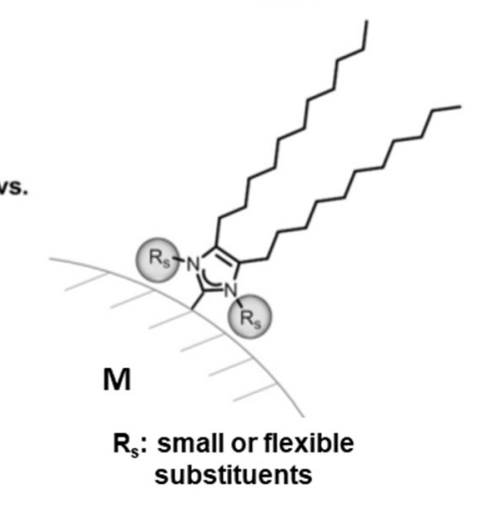

b) Direct surface bonding
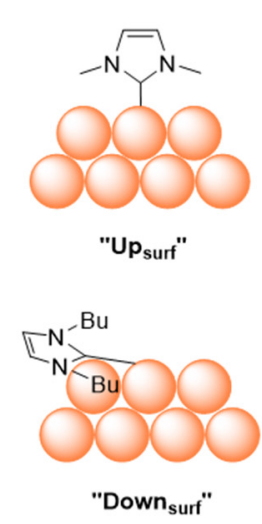

\section{Adatom bonding}
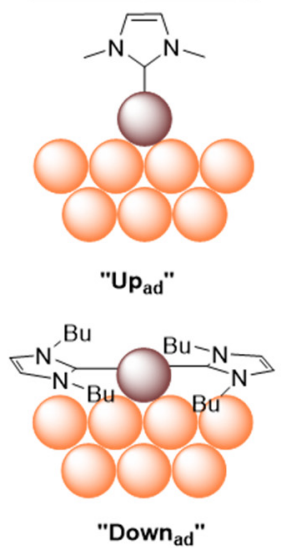

Figure 14. (a) Representation of NHC ligands with two different N-substituents. Extracted with permission from reference 51. Copyright 2014 The Royal Society of Chemistry. (b) Different binding modes of NHC ligands (IBu and IMe) to the metal surfaces. Adapted from reference 87 with permission of American Chemical Society.

Taking advantage of the great solubility and stability that these long alkyl chain NHC ligands confer to MNPs, Martínez-Prieto et al. prepared two types of Pt NPs stabilized with the same LC-NHC ligands (LC-IMe and LC-IPr; Figure 4c) [23]. Due to the high solubility in organic solvents of these Pt NPs, they were characterized by solution NMR, Diffusion-Ordered Spectroscopy (DOSY) and ESI-MS, among other techniques, obtaining valuable information about the NHC-metal interaction and the nanoparticle size distribution. For example, the diffusion coefficients of the free carbenes (LC-IMe and LC-IPr) observed by DOSY spectroscopy were higher than those corresponding to the $\mathrm{Pt}$ NPs, confirming the expected slower diffusion of the ligands bound to the nanoparticle surface in 
comparison with the free ones (Figure 15). In addition, only one diffusion coefficient was observed for $\mathrm{Pt} / \mathrm{LC}$-IPr, which indicates a narrow size distribution of these NPs, in contrast to the observation of different diffusion coefficients for Pt/LC-IMe, which points to a larger size distribution.
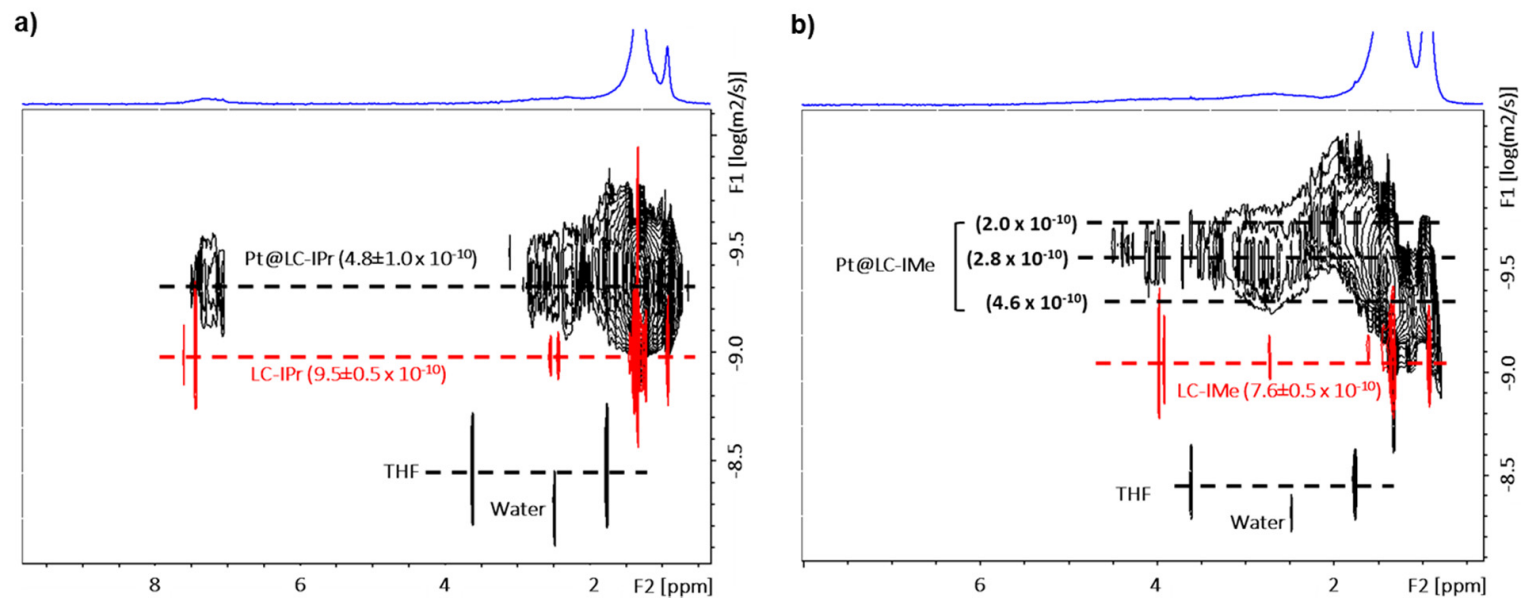

Figure 15. ${ }^{1} \mathrm{H}$ DOSY spectra of Pt/LC-IPr (black, (a)) and Pt/LC-IMe (black, (b)), together with their corresponding carbene precursors LC-IPr·HBr (red, (a)) and LC-IMe·HI (red, (b)) in THF-d ${ }^{8}$. Extracted with permission from reference 23. Copyright 2017 Willey-VCH.

Most of NHC ligands lack hydrophilic groups, which provide to the NHC-stabilized MNPs the polarity needed to be water-resistant. However, sulfonated NHC ligands (Figure 4e) have been successfully used as ancillary ligands for the stabilization of water-soluble MNPs [55-58,89,90]. The incorporation of the sulfonated group to the imidazole core confers to the NHC ligands a good solubility in polar solvents and makes MNPs stable in aqueous media. Martinez-Prieto et al. prepared MNPs stabilized with sulfonated NHC ligands for the first time following the organometallic approach [48], since previous examples of sulfonated NHC-stabilized MNPs were obtained by direct decomposition of metal NHC complexes [55-58] or ligand exchange [89]. In this work, taking advantage of the hydro-solubility of the Ru NPs, it was possible to monitor the interaction between the $\mathrm{L}_{\mathrm{L}}$-lysine and the MNP surface by chemical shift perturbation (CSP) in H/D exchange reactions. CSP experiments, normally used to investigate the protein/substrate interactions [91-93], were successfully employed to measure the substrate/MNP interaction by solution NMR. The information about the binding sites was obtained by ${ }^{1} \mathrm{H},{ }^{13} \mathrm{C}-\mathrm{HSQC}$ NMR after monitoring different quantities of $\mathrm{L}_{\text {-lysine into a }}$ $1 \mathrm{mg} \cdot \mathrm{mL}^{-1}$ solution of Ru NPs in $\mathrm{D}_{2} \mathrm{O}$ at different $\mathrm{pH}$ values. At $\mathrm{pH} 10.4$ the $\alpha$ and $\varepsilon$ positions of

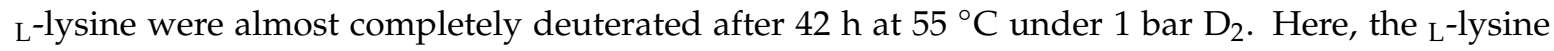
coordinates through $\alpha$ and $\varepsilon$ in a simultaneous or alternate way through the amino groups, explaining the high deuteration on these positions. At $\mathrm{pH} 13.2, \alpha$ and $\varepsilon$ positions were nearly fully deuterated, and $\gamma$ position was also deuterated due to the simultaneous interaction of the amino groups with the nanoparticle, pointing the protons in $\gamma$ to the metallic surface. At low $\mathrm{pH}$, in which the amino groups are protonated, the substrate-nanoparticle interaction is non-existent, and the activity is practically suppressed (see Figure 16). The same water-soluble Ru NPs were recently used by Pieters et al. for the hydrogen isotope exchange (HIE) of nucleobase pharmaceuticals and oligonucleotides, showing a good deuterium incorporation due to the high solubility in water of these hydrosoluble nanoparticles [26]. 


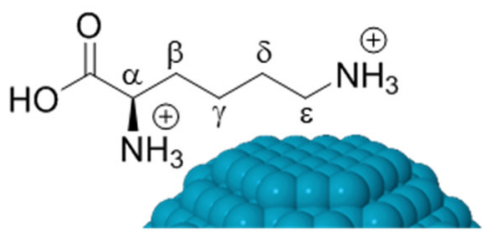

$\mathrm{pH} 3$

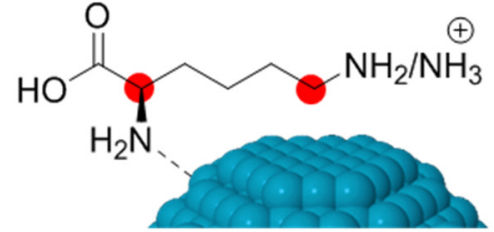

$\mathrm{pH} 10$

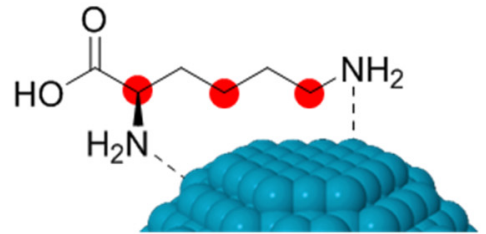

$\mathrm{pH} 13$

Figure 16. Coordination of $\mathrm{L}_{\mathrm{L}}$-lysine on $\mathrm{Ru} \mathrm{NP}$ surface as a function of $\mathrm{pH}$ in $\mathrm{D}_{2} \mathrm{O}$. Red pots correspond to the sites of the incorporation of deuterium in the hydrogen isotope exchange reactions. Adapted from reference 48 with permission of The Royal Society of Chemistry.

Using the same CSP method, Bouzouita et al. performed a similar interaction study by employing this time water-soluble bimetallic RuPt NPs [25]. Three different types of $\mathrm{IPrSO}_{3}$-stabilized RuPt NPs with distinct surface compositions were obtained by playing with the decomposition rate of the organometallic precursors used during the synthesis. In general terms, the slower the decomposition rate of the platinum precursor, the richer in platinum the surface was. Surface studies performed by solid-state NMR and FT-IR spectroscopies allowed the analysis of the relative surface composition of these bimetallic systems. Bimetallic NPs prepared by co-decomposition of $\mathrm{Ru}(\mathrm{COD})(\mathrm{COT})$ and $\mathrm{Pt}\left(\mathrm{CH}_{3}\right)_{2}(\mathrm{COD})$ were those with the higher $\mathrm{Pt} / \mathrm{Ru}$ ratio on their surface. Here, in contrast to monometallic $\mathrm{Ru}$ NPs, the $\mathrm{L}$-lysine coordinated to the RuPt surface through the amino and carboxylate groups, in a chelating way (Figure 17). This stronger interaction, as Sabatier's principle predicts [94], was reflected in a slower dissociation of the deuteration product that caused a slower reaction rate in $\alpha$ position.

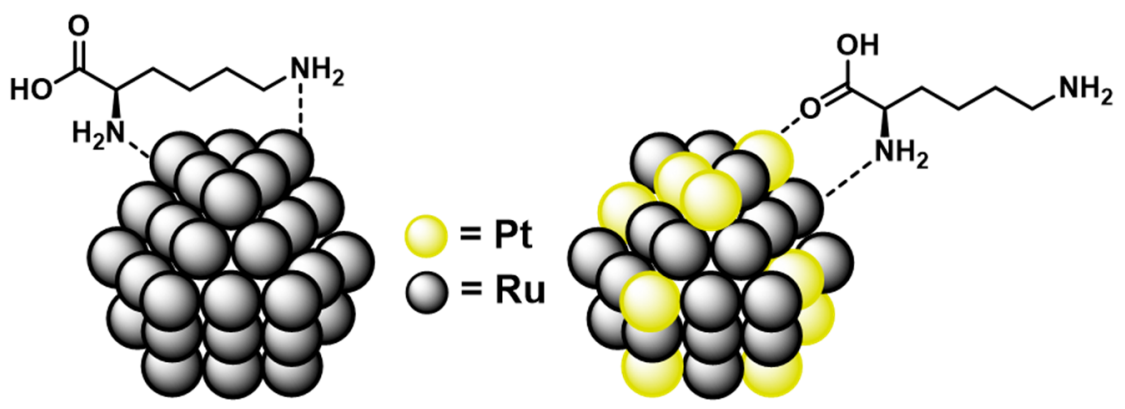

Figure 17. L-lysine interaction with Ru and RuPt NPs. Extracted with permission from reference 25. Copyright 2019 The Royal Society of Chemistry.

\subsection{Modifying the Catalytic Properties}

As discussed in the introduction, surface ligands in general and NHCs in particular are able to modify the catalytic performances among other properties of MNPs. By playing with the amount of stabilizing NHC ligand, or the nature of the carbene (i.e., bulky N-substituents, long alkyl chains groups in the imidazolium backbone, etc.), it is possible to control the activity/selectivity of the nanocatalysts-for example, NHC-stabilized organometallic Ru NPs reported by Lara et al. [12] exhibited a remarkable ligand effect in the hydrogenation of aromatic compounds [95]. Generally, $\mathrm{Ru} / \mathrm{IPr}_{0.2}$ showed the highest activity in comparison to $\mathrm{Ru} / \mathrm{IPr}_{0.5}$ and $\mathrm{Ru} / \mathrm{I} t \mathrm{Bu} \mathrm{u}_{0.5}$. First, the presence of an excess of ligand coordinated to the ruthenium surface slowed down the activity of the catalysts. In addition, the notable ligand effect observed $\left(\mathrm{Ru} / \mathrm{IPr}_{0.5}\right.$ being much more active than $\left.\mathrm{Ru} / \mathrm{I} t \mathrm{Bu}_{0.5}\right)$ was explained in terms of differences between ligand-surface interactions. The interaction of the bulky aromatic substituents of $\mathrm{Ru} / \mathrm{IPr}$ with the metal surface was weaker than the one with the $t \mathrm{Bu}$ groups, allowing an easier access of the aromatic substrates employed in the catalytic processes. Taking advantage of the new route to stabilize MNPs with non-isolable NHCs (see Section 2, Scheme 1), Martínez-Prieto et al. synthesized Ru NPs stabilized with chiral carbenes (Figure 4d; Ru/SIDPhNp and $\mathrm{Ru} / \mathrm{SIPhOH}$ ) with the aim of inducing enantioselectivity in the hydrogenation of different reactants [20]. 
The activity of these MNPs was tested in the hydrogenation of numerous prochiral substrates, without observing any enantiomeric excess. However, they showed good levels of catalytic activity and interesting differences in the hydrogenation of $\mathrm{C}=\mathrm{C}$ and $\mathrm{C}=\mathrm{O}$ bonds, $\mathrm{Ru} / \mathrm{SIDPhNp}$ being the most active. The general lower conversion observed for Ru-SIPhOH was explained in terms of the strong interaction of these ligands with the MNP surface, which reduces the access of the substrates to the active sites. This strong metal-ligand interaction was mainly due to the $\pi$-interactions between the metal surface and the aromatic rings and the probable coordination of the $-\mathrm{OH}$ groups to metal active sites. In a collaborative work Lara, Martínez-Prieto and co-workers synthesized and studied the surface of a great number of NHC-stabilized Ru NPs (Figure 4b), containing an asymmetric NHC [69]. Here, again, no enantiomeric excess was observed, in spite of the high activity and chemoselectivity of these chiral MNPs. The absence of chiral induction in these asymmetric hydrogenation reactions demonstrates that although surface ligands are able to control the catalytic behavior of MNPs, as well as in organometallic chemistry, it is often not feasible to extrapolate the catalytic performance of molecular complexes to ligand-stabilized MNPs.

In 2014, Lara et al. reported the first example of Pt NPs stabilized with NHCs and their use as catalysts in the selective hydrogenation of nitroaromatics [14]. In their study, the nature of the NHC ligand employed as a stabilizer and the MNP surface coverage ( 0.2 and 0.5 equiv. of two different NHCs (IPr and $\operatorname{IiPr}_{2} \mathrm{Me}_{2}$; Figure 4a,b)) showed an important influence on the catalytic activity in the hydrogenation of nitroaromatics. $\mathrm{Pt} / \mathrm{IPr}_{0.2}$ exhibited the best catalytic results, hydrogenating a great number of functionalize nitro compounds under mild conditions $\left(1 \mathrm{bar} \mathrm{H}_{2}, 30^{\circ} \mathrm{C}\right)$, with high levels of chemoselectivity ( $>99 \%$ at full conversion). The higher conversion of $\mathrm{Pt} / \operatorname{IPr}_{0.2} \mathrm{vs}$. $\mathrm{Pt} /\left(\mathrm{IiPr}_{2} \mathrm{Me}_{2}\right)_{0.2}$ and $\mathrm{Pt} / \mathrm{IPr}_{0.5}$ indicates that both the type of the ligand and surface coverage control the catalysts activity. In general, a higher surface coverage provides slower catalysts, since substrate access is more hindered, demonstrating once again that the proper choice of the number of surface ligands is essential to afford active catalysts.

Another illustrative example of the modulation of the catalytic activity of ligand-stabilized MNPs by adjusting the amount of surface ligands was reported by Martínez-Prieto et al. [71]. More specifically, the authors prepared Ru NPs with different quantities (0.1, 0.2 and 0.5 equiv.) of a derived-NHC ligand $\left(\mathrm{ICy} \cdot{ }^{(p-t o l)} \mathrm{NCN}\right)$, which strongly coordinates to the metal surface due to its zwitterionic character (Figure 18a). There, a clear dependence on NP size according to the amount of the amidinate ligand employed for the stabilization was observed: the MNP size decreases as the number of equivalents of stabilizing ligand increases. This size correlation was also found for NHC-stabilized MNPs (vide supra) [12] and other similar systems [46,96]. The smallest NPs $\left(\mathrm{Ru} / \mathrm{ICy} \cdot{ }^{(p-t o l)} \mathrm{NCN}_{0.2} ;\right.$ ca. $\left.1.0 \mathrm{~nm}\right)$, with a minor number of active sites located on the faces than the larger ones $\left(\mathrm{Ru} / \mathrm{ICy} \cdot{ }^{(p-t o l)} \mathrm{NCN}_{0.1}\right.$; ca. $1.3 \mathrm{~nm}$ ), showed a greater selectivity in the hydrogenation of styrene to ethylbenzene. Since available faces are essential for the hydrogenation of aromatic groups, the smaller size of $\mathrm{Ru} / \mathrm{ICy} \cdot{ }^{(p-t o l)} \mathrm{NCN}_{0.2}$, along with the higher number of surface ligand, established the catalytic activity of these ultra-small NPs in the frontier between molecular complexes and facetted NPs. Shortly after, Martínez-Prieto et al. were also able to control the catalytic activity of Pt NPs by modifying the electronic character of the $\mathrm{N}$-aryl substituents of these novel amidinate ligands [70]. The catalytic activity of these Pt NPs in the hydrogenation of activated ketones was highly dependent on the electron donor/acceptor capacity $(-\mathrm{Me},-\mathrm{OMe},-\mathrm{Cl})$ of the $\mathrm{N}$-substituents (Figure 18). The systems containing the electron-donating group (-OMe) showed the highest catalytic activity for these hydrogenation reactions, while those with electron-withdrawing groups $(-\mathrm{Cl})$ were the least active. Here, it was clearly evidenced that small modifications on the stabilizing ligands modulate the catalytic activity of MNPs. A similar ligand effect was recently reported by López Vinasco et al. in magnetic Ni NPs ligated by the same amidinate ligands in the partial hydrogenation of alkynes to alkenes [97]. The latter examples evidenced that both the number and nature of the stabilizing ligand play an important role in the activity and selectivity of MNPs in catalysis. 
a)

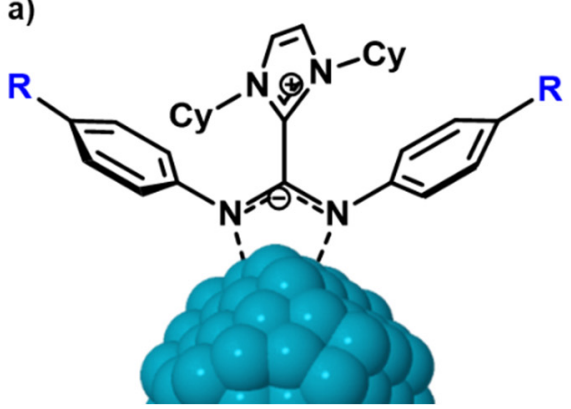

b)

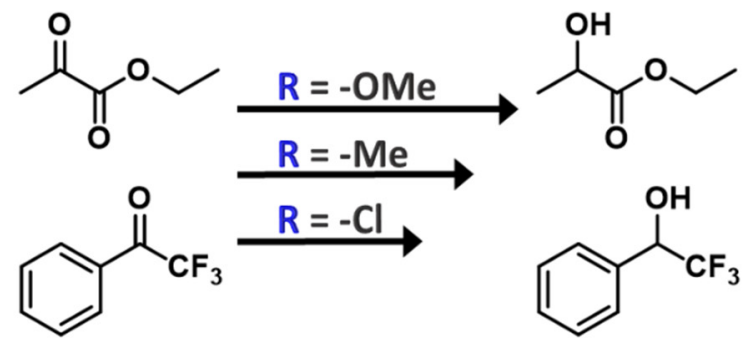

Figure 18. (a) Zwitterionic adduct of $N, N$-dicyclohexylimidazolidene and diarylcarbodiimide $\left(\mathrm{ICy} \cdot{ }^{(\mathrm{Ar})} \mathrm{NCN} ; \mathrm{Ar}=\mathrm{p}\right.$-tol, p-anisyl, $\mathrm{p}-\mathrm{ClC}_{6} \mathrm{H}_{4}$ ) coordinated to the MNP surface. (b) Ligand effect in the hydrogenation of activated ketones with Pt NPs stabilized by ICy. ${ }^{(\mathrm{Ar})} \mathrm{NCN}$. Reprinted with permission from reference 70. Copyright 2020 Springer.

The influence of surface ligands in MNP catalysis was also observed on Ru NPs stabilized with LC-NHC (Figure 4c) reported by Martínez-Prieto et al. [13]. The high stability of these Ru NPs due to the long alkyl chain linked to the backbone allowed their use as catalysts in hydrogenation and oxidation reactions. They were even active in an unprecedented reaction based in one-pot oxidation/hydrogenation process, where after the oxidation of the substrates, the atmosphere of $\mathrm{O}_{2}$ was replaced by $\mathrm{H}_{2}$ and the oxygenation products were selectively hydrogenated (Figure 19a). An interesting ligand effect was observed depending on the N-substituent of the NHC ligand (-Me or $\left.-(i \mathrm{Pr})_{2} \mathrm{Ph}\right)$. The less bulky the $\mathrm{N}$-substituent, the lower the number of free active sites and the poorer the activity. In fact, while $\mathrm{Ru} / \mathrm{LC}$-IPr totally hydrogenated acetophenone to ethylcyclohexane, $\mathrm{Ru} / \mathrm{LC}$-IMe was not able to hydrogenate it, showing an extremely different catalytic behavior. Therefore, the catalytic reactivity of these LC-NHC-stabilized Ru NPs was easily modified by changing their N-substituents. Pt NPs stabilized with the same LC-NHCs were also reported by Martinez-Prieto et al. in 2017 as the first example of hydroboration of phenylacetylene by non-supported platinum nanoparticles [23]. In the same way as in the previous work, a notable ligand effect on the catalytic activity of these $\mathrm{Pt}$ NPs was observed. Again, the bulkiness of the N-substituents controlled the MNP catalysis. Pt/LC-IPr with the bulkier substituent showed a high reactivity and selectivity in hydroboration reaction, as well as molecular Pt complexes, but Pt/LC-IMe NPs with larger diameter were not active in this type of reactions, as heterogeneous Pt catalysts (Figure 19b). Recently, it has been reported by Moraes et al. that Pt NPs stabilized by N-heterocyclic thiones (Figure 20) are also active in hydroboration of alkynes. The most active nanoparticles were those ligated to $\mathrm{NHT}^{\mathrm{Mes}}$, with low surface coverage, which presented excellent selectivities to the anti-Markonikov monoborylated product [24].

Another interesting ligand effect, this time involving NHCs derived from cholesterol [98], was reported by Rakers et al. in 2018 (Figure 21) [99]. These Ru NPs showed remarkable activity in the hydrogenation of arene derivatives, and a noticeable influence of the ligand due to their steric differences. Generally, Ru NPs ligated by NHCs with the cholesterol part on the N-substituent $(\mathrm{Ru} / \mathrm{IMe}-\mathrm{chol})$ displayed higher reactivity than those with the NHCs bearing the lipophilic fragment in the backbone of the imidazolium ring ( $\mathrm{Ru} / \mathrm{chol}-\mathrm{IMe})$. The higher activity of $\mathrm{Ru} / \mathrm{IMe}$-chol is again explained by the bulkiness of this carbene, which generates Ru NPs with a lower ligand coverage than $\mathrm{Ru} / \mathrm{chol}-\mathrm{IMe}$, and thus, more available faces that are essential for the hydrogenation of aromatic substrates. Apart from their activity in the hydrogenation of aromatics, as they are derived from cholesterol, these new nanosystems could have interesting possibilities as biological recognition systems. 
a)<smiles>CC(C)=CCC/C(C)=C/COC=O</smiles>

b)<smiles>C#Cc1ccccc1</smiles>

1<smiles>CC1(C)OBO1</smiles>

2

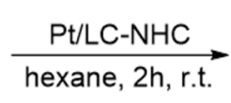

hexane, 2 h, r.t.<smiles>Brc1ccccc1</smiles>

3

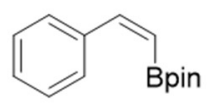

4

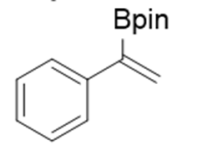

5

\begin{tabular}{cccc}
\hline Entry & Catalyst & Conversion(\%) & Yield (\%) \\
\hline 1 & $\mathrm{Pt} / \mathrm{LC}-\mathrm{IPr}$ & $>99$ & $3 / 4 / 5=81: 7: 8$ \\
2 & $\mathrm{Pt} / \mathrm{LC}-\mathrm{IMe}$ & 15 & Hydrogenation products \\
3 & $\mathrm{Pt} / \mathrm{C}$ & 28 & Hydrogenation products \\
4 & {$\left[\mathrm{Pt}(\mathrm{IPr}]_{2}\right]$} & 85 & $3 / 4 / 5=64: 3: 5$ \\
\hline
\end{tabular}

Figure 19. (a) One-pot oxidation-hydrogenation of geraniol catalyzed by Ru NPs stabilized with LC-NHCs. (b) Hydroboration of phenylacetylene catalyzed by Pt stabilized with LC-NHC. Adapted with permission from reference 23. Copyright 2017 Wiley-VCH.<smiles>Cc1c(C)n(C)c(=S)n1C</smiles>

NHT ${ }^{\mathrm{Me}}$<smiles>CCn1c(C)c(C)n(CC)c1=S</smiles>

$\mathrm{NHT}^{\mathrm{TPr}}$<smiles>CC(C)n1ccn(C(C)(C)C)c1=S</smiles>

$\mathrm{n}=5 ; \mathrm{NHT}^{\mathrm{C} 6}$

$\mathrm{n}=13, \mathrm{NHT}^{\mathrm{C} 14}$

$\mathrm{n}=17 ; \mathrm{NHT}^{\mathrm{C} 18}$

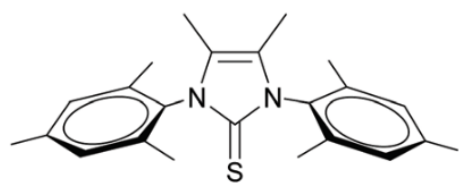

$\mathrm{NHT}^{\text {Mes }}$

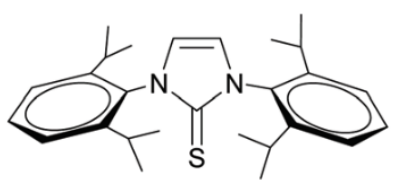

$\mathrm{NHT}^{\mathrm{TPr}}$

Figure 20. N-Heterocyclic thiones used in reference 24 by Moraes et al. Reproduced with permission from reference 24. Copyright 2020 The Royal Society of Chemistry.

All the examples discussed until now were focused on the possibility to control the physicochemical properties of ligand-stabilized colloidal MNPs by modulating the NHC ligands present at their surface. Nevertheless, it is also possible to control the surface properties of supported MNPs through their functionalization with NHCs $[18,52,100]$, thus modifying their selectivity or activity. As is known, since improving the selectivity of heterogeneous catalysts is always a challenge, the modification of supported MNPs with surface NHCs ligands can have a great potential for industrial applications [101]. In this line, there are few recent examples of controlling the activity and selectivity of supported $\mathrm{Ru}$ NPs by the coordination of NHC ligands on the metallic surface. For example, in 2016, Glorius in collaboration with Muratsugu reported the functionalization of Ru NPs supported on potassium-doped alumina ( $\left.\mathrm{Ru} / \mathrm{K}-\mathrm{Al}_{2} \mathrm{O}_{3}\right)$ with two different NHC ligands (ICy and IMes) [102]. These NHC-modified supported heterogeneous catalysts were tested in the hydrogenation of numerous reactants with the 
intention of studying the effect of the surface functionalization on their catalytic properties. First, a clear dependence of the catalytic activity with the amount of surface ligands was observed in the hydrogenation of trans-stilbene and acetophenone. The activity decreased as the number of coordinated NHC ligands increased, this trend being more marked for $\mathrm{K}-\mathrm{Al}_{2} \mathrm{O}_{3}$-supported $\mathrm{Ru} \mathrm{NPs}$ functionalized with the bulkiest NHC ligand (IMes), which in principle blocks more surface active sites. Moreover, a remarkable influence of the surface coverage was observed in the selective hydrogenation of phenylacetylene to ethylbenzene; the larger the amount of surface NHC ligands, the higher the selectivity to ethylbenzene (Figure 22a). Again, this trend was more pronounced for $\mathrm{Ru} / \mathrm{K}-\mathrm{Al}_{2} \mathrm{O}_{3} @ \mathrm{IM} \mathrm{Mes}$, which presented the bulkier $\mathrm{N}$-substituent. Some years before, the same group reported the preparation of Pd nanoparticles supported on $\mathrm{Fe}_{3} \mathrm{O}_{4}$ and their later treatment with a chiral NHC in order to modify the surface of the catalyst and induce enantioselectivity in asymmetric reactions [18]. More precisely, the supported $\mathrm{Pd} / \mathrm{Fe}_{3} \mathrm{O}_{4} \mathrm{NPs}$ were modified by a treatment with the imidazolium salt of an enantiomerically pure NHC in the presence of a base (Figure 22b). The resulting catalyst was fully characterized by a combination of different techniques (XPS, FT-IR, TEM, SEM), and its catalytic activity was evaluated in the asymmetric $\alpha$-arylation of ketones, showing in a couple of cases enantiomeric excess higher than $80 \%$. The magnetic recycling of the catalyst was also studied, showing the preservation of their catalytic activity and selectivity after five catalytic cycles. Another interesting example of functionalization of heterogeneous Ru catalysts with NHC ligands was recently reported by Pieters et al. [103]. The authors found that it is possible to control the activity and selectivity of a commercially available heterogeneous $\mathrm{Ru}$ catalyst ( $\mathrm{Ru}$ on carbon; $\mathrm{Ru} / \mathrm{C}$ ) in hydrogen isotope exchange (HIE) reactions by adding NHC ligands, being the first example of ligand induced modification of heterogeneous catalysts in the context of $\mathrm{C}-\mathrm{H}$ activation. More specifically, they reported a general method for the selective $\mathrm{C}-\mathrm{H}$ deuteration of $\alpha$-positions on alcohols, pharmaceutical relevant heterocycles and aldehydes, promoting the H/D exchange processes over reduction side reactions (Figure 23). In general, the use of $\mathrm{Ru} / \mathrm{C}$ produces a mixture of labeled (HIE) and reduced products (reductive deuteration). However, the catalyst modification by adding NHCs promotes the H/D exchange over the reductive deuteration. Therefore, the functionalization of $\mathrm{Ru} / \mathrm{C}$ with $\mathrm{NHC}$ sallowed the selective deuteration of aromatic compounds with pharmaceutical interest that otherwise cannot be obtained due to reductive side reactions. In addition to these examples, there are a few more studies where it is possible to control the stereoselectivity or chemoselectivity of supported MNPs through their functionalization with NHC ligands [52,100]. Therefore, post-ligand functionalization of supported MNPs is an emerging field with great industrial interest, since it combines the advantages of homogeneous and heterogeneous catalysis (i.e., activity, selectivity and stability).

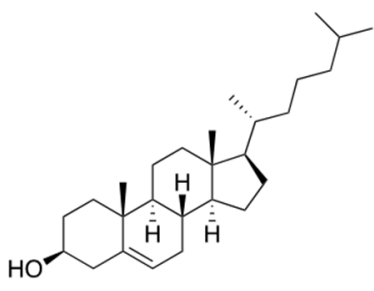

cholesterol

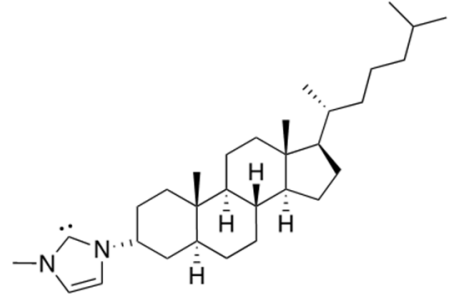

IMe-chol

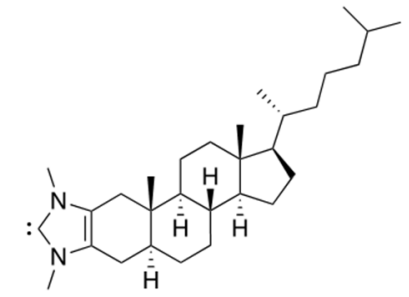

chol-IMe

Figure 21. Cholesterol (left) and NHC ligands derived from cholesterol (right) used for Ru NP stabilization. Adapted from reference 99. Copyright 2018 The Royal Society of Chemistry. 
a)
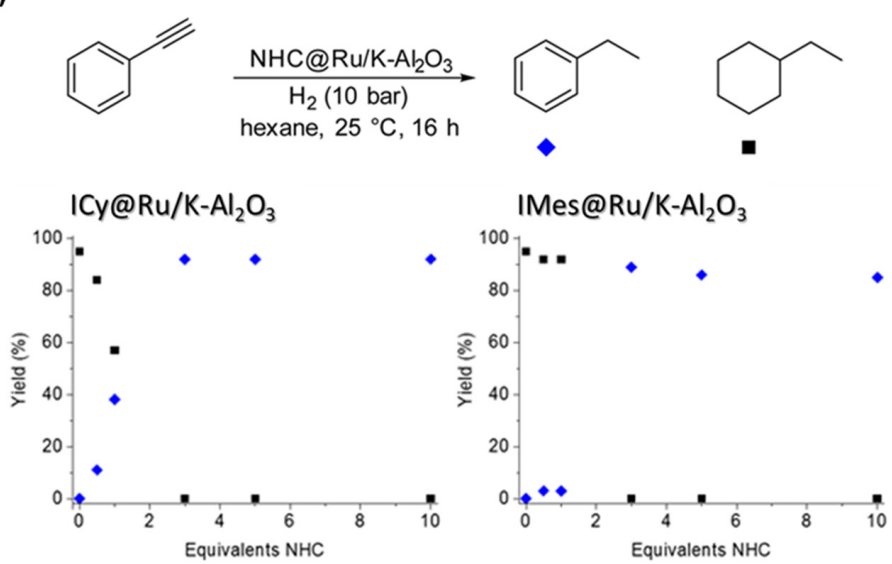

b)

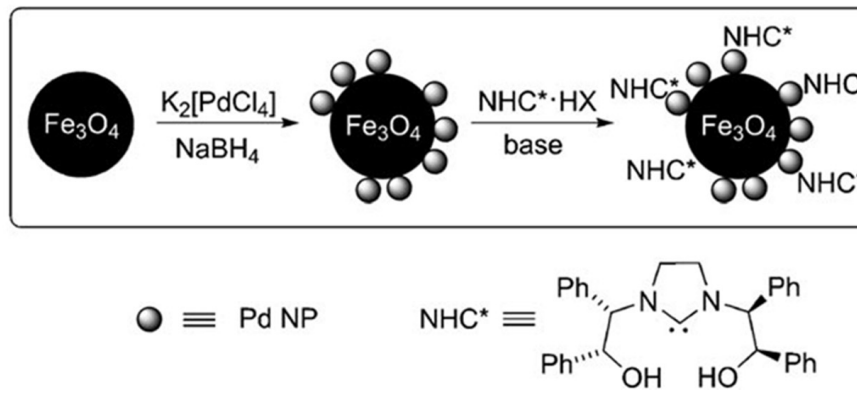

Figure 22. (a) Influence of NHC-loading on the chemoselectivity in the hydrogenation of phenylacetylene. Extracted from reference 102. Copyright 2016 American Chemical Society. (b) Synthesis of $\mathrm{Fe}_{3} \mathrm{O}_{4} / \mathrm{Pd}$ NPs modified by chiral NHCs. Reproduced from reference 18. Copyright 2010 Willey-VCH.
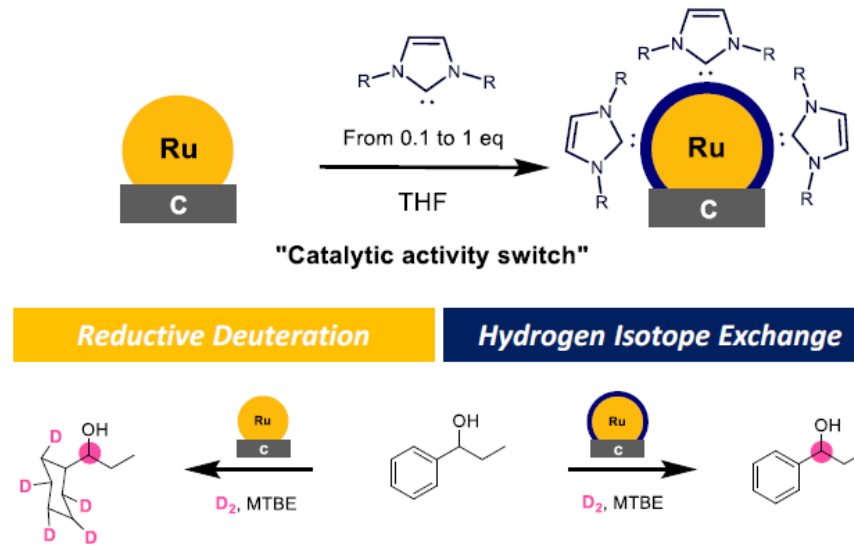<smiles>CCC(O)c1ccccc1</smiles>
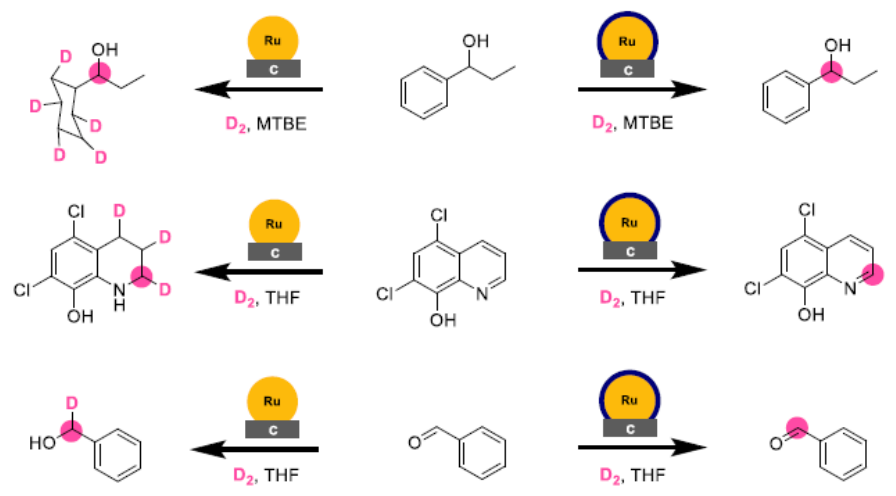

Major site of isotope incorporation via Hydrogen Isotope Exchange (HIE)

Figure 23. (Top): Synthesis of Ru on carbon modified with NHCs (NHC@Ru/C). (Bottom): Catalytic activity switch due to the functionalization of $\mathrm{Ru} / \mathrm{C}$ with NHCs. Reproduced from reference 103. Copyright 2020 Willey-VCH. 


\section{Conclusions}

In this review, we have explored the ability of NHC ligands to stabilize and modulate the catalytic properties of MNPs, focusing the survey on organometallic nanoparticles prepared by an organometallic approach, which produces clean surface MNPs ideal for surface studies and catalytic applications. Since the first example of Ru NPs stabilized with isolable NHCs was reported [12], their synthesis has evolved, as the stabilization of organometallic NPs with non-isolable NHCs is now possible. This can be performed by the in-situ formation of the free carbene [20] or by using an NHC- $\mathrm{CO}_{2}$ adduct as carbene precursor [49]. These new approaches have proven to be quite versatile for the stabilization of multitude of NHC-stabilized organometallic NPs (Pt, $\mathrm{Ru}, \mathrm{Ni}$, etc.).

The strong ligand-metal interaction and clean surface of these NHC-stabilized organometallic NPs make them perfect nano-objects for surface investigations. MAS NMR, FT-IR and XPS have been established as effective tools to determine both the coordination of NHC ligands on the MNP surface and the location of their available active sites. For example, NHC coordination has been definitively proven by ${ }^{13} \mathrm{C}$ MAS-NMR through the determination of the ${ }^{13} \mathrm{C}-{ }^{195} \mathrm{Pt}$ coupling constant between the labeled ligand and the MNP [55] and the observation of Knight shift in the coordinated carbenic carbon [57]. In addition, by using CO as a probe molecule, the different surface states of NHC-stabilized MNPs can be easily determined by FT-IR and MAS-NMR. As a rule, the location and number of active sites mainly depend on the nature and the amount of surface NHC ligands. Moreover, as has been observed along this revision, the number of equivalents and the structure of the stabilizing NHC ligand also influence the MNP properties such as stability, solubility and catalytic activity/selectivity. Changes on the N-substituents (e.g., incorporation of a bulky group) or adjustments in the imidazolium ring (e.g., presence of a long alkyl chain) are reflected in the modification of the physicochemical properties of MNPs. For example, the bulkier the N-substituent, the larger the amount of free active sites and higher the catalytic activity results.

Finally, NHCs have also demonstrated their capacity to tune the catalytic properties of supported MNPs, being able to modify their activity or selectivity, which results in great interest due to the fact that reaching a good control of the selectivity of heterogeneous catalysts is one of the major challenges in industrial catalysis. These catalytic systems unify the benefits of heterogeneous catalysts (stability) and NHC-stabilized MNPs (selectivity).

Therefore, to summarize, in this review, we have shown the capability of NHC ligands to modify the catalytic properties of MNPs, providing important insights in an emerging field: influence of stabilizing ligands in metal nanoparticle catalysis.

Author Contributions: Individual contributions of all authors are specified as follows: writing-original draft preparation, C.C.-N.; writing-review and editing, P.L., L.M.M.-P.; supervision, L.M.M.-P. All authors have read and agreed to the published version of the manuscript.

Funding: This research was funded by: Proyectos Intramurales Especiales (201880E079), Primero Proyectos de Investigación PAID-06-18 (SP20180088), Agencia Estatal de Investigación (PID2019-104159GB-I00/AEI/ 10.13039/501100011033) and Junta de Andalucía (PY18-3208).

Acknowledgments: The authors thank Instituto de Tecnología Química (ITQ), Consejo Superior de Investigaciones Científicas (CSIC), Universitat Politècnica de València (UPV), Departamento de Química Inorgánica (University of Seville), Institute for Chemical Research (IIQ) for the facilities and Severo Ochoa excellence programme, C.C.-N. thanks Generalitat Valenciana for the predoctoral GVA fellowship (ACIF/2019/076). We gratefully acknowledge B. Chaudret for his invaluable contribution to this research area and his sincere friendship.

Conflicts of Interest: There are no conflicts to declare.

\section{References}

1. Astruc, D. Nanoparticles and Catalysis; Wiley-VCH: Weinheim, Germany, 2008.

2. Serp, P.; Philippot, K. Nanomaterials in Catalysis; Wiley-VCH: Weinheim, Germany, 2013. 
3. Martínez-Prieto, L.M.; Van Leeuwen, P.W.N.M. Ligand effects in ruthenium nanoparticle catalysis. In Recent Advances in Nanoparticle Catalysis; Springer Science and Business Media: New York, NY, USA, 2020; pp. 407-448.

4. Hopkinson, M.N.; Richter, C.; Schedler, M.; Glorius, F. An overview of N-heterocyclic carbenes. Nature 2014, 510, 485-496. [CrossRef]

5. Smith, C.A.; Narouz, M.R.; Lummis, P.A.; Singh, I.; Nazemi, A.; Huang, C.-J.; Crudden, C.M. N-heterocyclic carbenes in materials chemistry. Chem. Rev. 2019, 119, 4986-5056. [CrossRef]

6. Arduengo, A.J.; Harlow, R.L.; Kline, M. A stable crystalline carbene Erratum to document cited in CA114(7):62009r. J. Am. Chem. Soc. 1991, 113, 2801. [CrossRef]

7. Bourissou, D.; Guerret, O.; Gabbaï, F.P.; Bertrand, G. Stable carbenes. Chem. Rev. 2000, 100, 39-92. [CrossRef]

8. De Frémont, P.; Marion, N.; Nolan, S.P. Carbenes: Synthesis, properties, and organometallic chemistry. Co-Ord. Chem. Rev. 2009, 253, 862-892. [CrossRef]

9. Herrmann, W.A.; GooßenL, J.; Spiegler, M. Functionalized imidazoline -2- ylidene complexes of rhodium and palladium. J. Organomet. Chem. 1997, 547, 357-366. [CrossRef]

10. Poyatos, M.; Mata, J.A.; Peris, E. Complexes with poly (N-heterocyclic carbene) ligands: Structural features and catalytic applications. Chem. Rev. 2009, 109, 3677-3707. [CrossRef]

11. Schaper, L.-A.; Hock, S.J.; Herrmann, W.A.; Kühn, F.E. Synthesis and application of water-soluble NHC transition-metal complexes. Angew. Chem. Int. Ed. 2012, 52, 270-289. [CrossRef]

12. Lara, P.; Conejero, S.; Rivada-Wheelaghan, O.; Poteau, R.; Philippot, K.; Chaudret, B. Ruthenium nanoparticles stabilized by N-heterocyclic carbenes: Ligand location and influence on reactivity. Angew. Chem. Int. Ed. 2011, 50, 12080-12084. [CrossRef]

13. Martínez-Prieto, L.M.; Ferry, A.; Rakers, L.; Richter, C.; Lecante, P.; Philippot, K.; Chaudret, B.; Glorius, F. Long-chain NHC-stabilized RuNPs as versatile catalysts for one-pot oxidation/hydrogenation reactions. Chem. Commun. 2016, 52, 4768-4771. [CrossRef]

14. Lara, P.; Suárez, A.; Collière, V.; Philippot, K.; Chaudret, B. Platinum N-heterocyclic carbene nanoparticles as new and effective catalysts for the selective hydrogenation of nitroaromatics. ChemCatChem 2013, 6, 87-90. [CrossRef]

15. Ranganath, K.V.S.; Schäfer, A.; Glorius, F. Comparison of superparamagnetic $\mathrm{Fe}_{3} \mathrm{O}_{4}$-supported N-heterocyclic carbene-based catalysts for enantioselective allylation. ChemCatChem 2011, 3, 1889-1891. [CrossRef]

16. Mollar-Cuni, A.; Ventura-Espinosa, D.; Martín, S.; Mayoral, A.; Borja, P.; Mata, J.A. Stabilization of nanoparticles produced by hydrogenation of palladium-N-heterocyclic carbene complexes on the surface of graphene and implications in catalysis. ACS Omega 2018, 3, 15217-15228. [CrossRef]

17. Hurst, E.C.; Wilson, K.; Fairlamb, I.J.S.; Chechik, V. N-Heterocyclic carbene coated metal nanoparticles. New J. Chem. 2009, 33, 1837-1840. [CrossRef]

18. Ranganath, K.V.S.; Kloesges, J.; Schäfer, A.H.; Glorius, F. Asymmetric nanocatalysis: N-heterocyclic carbenes as chiral modifiers of $\mathrm{Fe}_{3} \mathrm{O}_{4} / \mathrm{Pd}$ nanoparticles. Angew. Chem. Int. Ed. 2010, 49, 7786-7789. [CrossRef] [PubMed]

19. Planellas, M.; Pleixats, R.; Shafir, A. Palladium nanoparticles in Suzuki cross-couplings: Tapping into the potential of tris-imidazolium salts for nanoparticle stabilization. Adv. Synth. Catal. 2012, 354, 651-662. [CrossRef]

20. Martínez-Prieto, L.M.; Ferry, A.; Lara, P.; Richter, C.; Philippot, K.; Glorius, F.; Chaudret, B. New route to stabilize ruthenium nanoparticles with non-isolable chiral N-heterocyclic carbenes. Chem. A Eur. J. 2015, 21, 17495-17502. [CrossRef] [PubMed]

21. Hintermair, U.; Hashmi, S.M.; Elimelech, M.; Crabtree, R.H. Particle formation during oxidation catalysis with Cp iridium complexes. J. Am. Chem. Soc. 2012, 134, 9785-9795. [CrossRef]

22. Axet, M.; Conejero, S.; Gerber, I.C. Ligand effects on the selective hydrogenation of nitrobenzene to cyclohexylamine using ruthenium nanoparticles as catalysts. ACS Appl. Nano Mater. 2018, 1, 5885-5894. [CrossRef]

23. Martínez-Prieto, L.M.; Rakers, L.; López-Vinasco, A.M.; Cano, I.; Coppel, Y.; Philippot, K.; Glorius, F.; Chaudret, B.; Van Leeuwen, P.W.N.M. Soluble platinum nanoparticles ligated by long-chain N-heterocyclic carbenes as catalysts. Chem. A Eur. J. 2017, 23, 12779-12786. [CrossRef] 
24. Moraes, L.C.; Figueiredo, R.C.; Espinós, J.P.; Vattier, F.; Franconetti, A.; Jaime, C.; Lacroix, B.; Rojo, J.; Lara, P.; Conejero, S. Platinum nanoparticles stabilized by N-heterocyclic thiones. Synthesis and catalytic activity in mono-and di-hydroboration of alkynes. Nanoscale 2020, 12, 6821-6831. [CrossRef] [PubMed]

25. Bouzouita, D.; Lippens, G.; Baquero, E.A.; Fazzini, P.-F.; Pieters, G.; Coppel, Y.; Lecante, P.; Tricard, S.; Martínez-Prieto, L.M.; Chaudret, B. Tuning the catalytic activity and selectivity of water-soluble bimetallic RuPt nanoparticles by modifying their surface metal distribution. Nanoscale 2019, 11, 16544-16552. [CrossRef] [PubMed]

26. Palazzolo, A.; Feuillastre, S.; Pfeifer, V.; Garcia-Argote, S.; Certiat, M.; Bouzouita, D.; Marcon, E.; Buisson, D.-A.; Lesot, P.; Chaudret, B.; et al. Hydrogen isotope exchange catalyzed by Ru nonocatalysts: Labelling of complex molecules containing N-heterocycles and reaction mechanism insights. Chem. Eur. J. 2020, 22. [CrossRef]

27. Amiens, C.; Chaudret, B.; Ciuculescu-Pradines, D.; Collière, V.; Fajerwerg, K.; Fau, P.; Kahn, M.; Maisonnat, A.; Soulantica, K.; Philippot, K. Organometallic approach for the synthesis of nanostructures. New J. Chem. 2013, 37, 3374-3401. [CrossRef]

28. Martínez-Prieto, L.M.; Chaudret, B. Organometallic Ruthenium Nanoparticles: Synthesis, Surface Chemistry, and Insights into Ligand Coordination. Acc. Chem. Res. 2018, 51, 376-384. [CrossRef] [PubMed]

29. Bradley, J.S.; Millar, J.; Hill, E.W.; Melchior, M. The characterization of adsorbed carbon monoxide on colloidal palladium by infrared and high resolution 13C nuclear magnetic resonance spectroscopy. J. Chem. Soc. Chem. Commun. 1990, 705. [CrossRef]

30. Bradley, J.S.; Hill, E.W.; Behal, S.; Klein, C.; Duteil, A.; Chaudret, B. Preparation and characterization of organosols of monodispersed nanoscale palladium. Particle size effects in the binding geometry of adsorbed carbon monoxide. Chem. Mater. 1992, 4, 1234-1239. [CrossRef]

31. Novio, F.; Philippot, K.; Chaudret, B. Location and dynamics of CO co-ordination on Ru nanoparticles: A solid state NMR study. Catal. Lett. 2010, 140, 1-7. [CrossRef]

32. Rühling, A.; Schaepe, K.; Rakers, L.; Vonhören, B.; Tegeder, P.; Ravoo, B.J.; Glorius, F. Modular bidentate hybrid NHC-thioether ligands for the stabilization of palladium nanoparticles in various solvents. Angew. Chem. Int. Ed. 2016, 55, 5856-5860. [CrossRef]

33. Bradley, J.S.; Millar, J.M.; Hill, E.W.; Behal, S.; Chaudret, B.; Duteil, A. Surface chemistry on colloidal metals: Spectroscopic study of adsorption of small molecules. Faraday Discuss. 1991, 92, 255-268. [CrossRef]

34. Cormary, B.; Dumestre, F.; Liakakos, N.; Soulantica, K.; Chaudret, B. Organometallic precursors of nano-objects, a critical view. Dalton Trans. 2013, 42, 12546. [CrossRef] [PubMed]

35. Marbaix, J.; Mille, N.; Lacroix, L.-M.; Asensio, J.M.; Fazzini, P.-F.; Soulantica, K.; Carrey, J.; Chaudret, B. Tuning the composition of FeCo nanoparticle heating agents for magnetically induced catalysis. ACS Appl. Nano Mater. 2020, 3, 3767-3778. [CrossRef]

36. Martínez-Prieto, L.M.; Marbaix, J.; Asensio, J.M.; Cerezo-Navarrete, C.; Fazzini, P.-F.; Soulantica, K.; Chaudret, B.; Corma, A. Ultrastable magnetic nanoparticles encapsulated in carbon for magnetically induced catalysis. ACS Appl. Nano Mater. 2020, 3, 7076-7087. [CrossRef] [PubMed]

37. García-Antón, J.; Axet, M.; Jansat, S.; Philippot, K.; Chaudret, B.; Pery, T.; Buntkowsky, G.; Limbach, H.H. Reactions of olefins with ruthenium hydride nanoparticles: NMR characterization, hydride titration, and room-temperature C-C bond activation. Angew. Chem. Int. Ed. 2008, 47, 2074-2078. [CrossRef] [PubMed]

38. Lara, P.; Philippot, K.; Chaudret, B. Organometallic ruthenium nanoparticles: A comparative study of the influence of the stabilizer on their characteristics and reactivity. ChemCatChem 2012, 5, 28-45. [CrossRef]

39. Axet, M.; Philippot, K. Catalysis with colloidal ruthenium nanoparticles. Chem. Rev. 2020, 120, 1085-1145. [CrossRef] [PubMed]

40. Dupont, J.; Fonseca, G.S.; Umpierre, A.P.; Fichtner, P.F.P.; Teixeira, S.R. Transition-metal nanoparticles in imidazolium ionic liquids: Recycable catalysts for biphasic hydrogenation reactions. J. Am. Chem. Soc. 2002, 124, 4228-4229. [CrossRef]

41. Vidoni, O.; Philippot, K.; Amiens, C.; Chaudret, B.; Balmes, O.; Malm, J.-O.; Bovin, J.-O.; Senocq, F.; Casanove, M. Novel, spongelike ruthenium particles of controllable size stabilized only by organic solvents. Angew. Chem. Int. Ed. 1999, 38, 3736-3738. [CrossRef]

42. Hulea, V.; Brunel, D.; Galarneau, A.; Philippot, K.; Chaudret, B.; Kooyman, P.J.; Fajula, F. Synthesis of well-dispersed ruthenium nanoparticles inside mesostructured porous silica under mild conditions. Microporous Mesoporous Mater. 2005, 79, 185-194. [CrossRef] 
43. Glaria, A.; Soulé, S.; Hallali, N.; Ojo, W.-S.; Mirjolet, M.; Fuks, G.; Cornejo, A.; Allouche, J.; Dupin, J.C.; Martinez, H.; et al. Silica coated iron nanoparticles: Synthesis, interface control, magnetic and hyperthermia properties. RSC Adv. 2018, 8, 32146-32156. [CrossRef]

44. Martínez-Prieto, L.M.; Puche, M.; Cerezo, C.; Chaudret, B. Uniform Ru nanoparticles on N-doped graphene for selective hydrogenation of fatty acids to alcohols. J. Catal. 2019, 377, 429-437. [CrossRef]

45. Vignolle, J.; Tilley, T.D. N-Heterocyclic carbene-stabilized gold nanoparticles and their assembly into 3D superlattices. Chem. Commun. 2009, 7230. [CrossRef]

46. Pan, C.; Pelzer, K.; Philippot, K.; Chaudret, B.; Dassenoy, F.; Lecante, P.; Casanove, M.-J. Ligand-stabilized ruthenium nanoparticles: Synthesis, organization, and dynamics. J. Am. Chem. Soc. 2001, 123, 7584-7593. [CrossRef] [PubMed]

47. Martinez-Espinar, F.; Blondeau, P.; Nolis, P.; Chaudret, B.; Claver, C.; Castillón, S.; Godard, C. NHC-stabilised Rh nanoparticles: Surface study and application in the catalytic hydrogenation of aromatic substrates. J. Catal. 2017, 354, 113-127. [CrossRef]

48. Martínez-Prieto, L.M.; Baquero, E.A.; Pieters, G.; Flores, J.C.; De Jesús, E.; Nayral, C.; Delpech, F.; Van Leeuwen, P.W.N.M.; Lippens, G.; Chaudret, B. Monitoring of nanoparticle reactivity in solution: Interaction of l- lysine and Ru nanoparticles probed by chemical shift perturbation parallels regioselective H/D exchange. Chem. Commun. 2017, 53, 5850-5853. [CrossRef] [PubMed]

49. Bernardos, M.D.D.L.; Pérez-Rodríguez, S.; Gual, A.; Claver, C.; Godard, C. Facile synthesis of NHC-stabilized $\mathrm{Ni}$ nanoparticles and their catalytic application in the Z-selective hydrogenation of alkynes. Chem. Commun. 2017, 53, 7894-7897. [CrossRef]

50. Voutchkova, A.M.; Appelhans, L.N.; Chianese, A.R.; Crabtree, R.H. Disubstituted imidazolium -2carboxylates as efficient precursors to N-heterocyclic carbene complexes of $\mathrm{Rh}, \mathrm{Ru}$, Ir and Pd. J. Am. Chem. Soc. 2005, 127, 17624-17625. [CrossRef]

51. Richter, C.; Schaepe, K.; Glorius, F.; Ravoo, B.J. Tailor-made N-heterocyclic carbenes for nanoparticle stabilization. Chem. Commun. 2014, 50, 3204. [CrossRef]

52. Ye, R.; Zhukhovitskiy, A.V.; Kazantsev, R.V.; Fakra, S.C.; Wickemeyer, B.B.; Toste, F.D.; Somorjai, G.A. Supported $\mathrm{Au}$ Nanoparticles with $\mathrm{N}$-heterocyclic carbene ligands as active and stable heterogeneous catalysts for lactonization. J. Am. Chem. Soc. 2018, 140, 4144-4149. [CrossRef]

53. Man, R.W.Y.; Huang, C.-J.; MacLean, M.W.A.; Zenkina, O.V.; Zamora, M.T.; Saunders, L.N.; Rousina-Webb, A.; Nambo, M.; Crudden, C.M. Ultrastable gold nanoparticles modified by bidentate N-heterocyclic carbene ligands. J. Am. Chem. Soc. 2018, 140, 1576-1579. [CrossRef]

54. Lu, H.; Zhou, Z.; Prezhdo, O.V.; Brutchey, R.L. Exposing the dynamics and energetics of the N-Heterocyclic carbene-nanocrystal interface. J. Am. Chem. Soc. 2016, 138, 14844-14847. [CrossRef] [PubMed]

55. Baquero, E.A.; Tricard, S.; Flores, J.C.; De Jesús, E.; Chaudret, B. Highly stable water-soluble platinum nanoparticles stabilized by hydrophilic N-heterocyclic carbenes. Angew. Chem. Int. Ed. 2014, 53, 13220-13224. [CrossRef] [PubMed]

56. Baquero, E.A.; Tricard, S.; Coppel, Y.; Flores, J.C.; Chaudret, B.; De Jesús, E. Water-soluble platinum nanoparticles stabilized by sulfonated N-heterocyclic carbenes: Influence of the synthetic approach. Dalton Trans. 2018, 47, 4093-4104. [CrossRef] [PubMed]

57. Asensio, J.M.; Tricard, S.; Coppel, Y.; Andrés, R.; Chaudret, B.; De Jesús, E.; Revert, J.M.A. Knight Shift in 13C NMR resonances confirms the coordination of N-heterocyclic carbene ligands to water-soluble palladium nanoparticles. Angew. Chem. Int. Ed. 2016, 56, 865-869. [CrossRef]

58. Asensio, J.M.; Tricard, S.; Coppel, Y.; Andrés, R.; Chaudret, B.; De Jesús, E. Synthesis of water-soluble palladium nanoparticles stabilized by sulfonated N-heterocyclic carbenes. Chem. A Eur. J. 2017, 23, 13435-13444. [CrossRef]

59. Duncan, T.M.; Zilm, K.W.; Hamilton, D.M.; Root, T.W. Adsorbed states of carbon monoxide on dispersed metals: A high-resolution solid-state NMR study. J. Phys. Chem. 1989, 93, 2583-2590. [CrossRef]

60. Terrill, R.H.; Postlethwaite, T.A.; Chen, C.-H.; Poon, C.-D.; Terzis, A.; Chen, A.; Hutchison, J.E.; Clark, M.R.; Wignall, G. Monolayers in three dimensions: NMR, SAXS, thermal, and electron hopping studies of alkanethiol stabilized gold clusters. J. Am. Chem. Soc. 1995, 117, 12537-12548. [CrossRef]

61. Badia, A.; Cuccia, L.; Demers, L.; Morin, F.; Lennox, R.B. Structure and dynamics in alkanethiolate monolayers self-assembled on gold nanoparticles: A DSC, FT-IR, and deuterium NMR study. J. Am. Chem. Soc. 1997, 119, 2682-2692. [CrossRef] 
62. Ramírez-Meneses, E.; Jansat, S.; Philippot, K.; Lecante, P.; Gómez, M.; Masdeu-Bultó, A.M.; Chaudret, B. Influence of organic ligands on the stabilization of palladium nanoparticles. J. Organomet. Chem. 2004, 689, 4601-4610. [CrossRef]

63. Pregosin, P.S.; Ammann, C. Applications of 2-dimensional NMR in organometallic chemistry. Pure Appl. Chem. 1989, 61, 1771-1776. [CrossRef]

64. Bradley, J.S.; Millar, J.M.; Hill, E.W.; Behal, S. Surface chemistry on transition metal colloids?an infrared and NMR study of carbon monoxide adsorption on colloidal platinum. J. Catal. 1991, 129, 530-539. [CrossRef]

65. Bradley, J.S.; Millar, J.M.; Hill, E.W. Surface chemistry on colloidal metals: A high-resolution NMR study of carbon monoxide adsorbed on metallic palladium crystallites in colloidal suspension. J. Am. Chem. Soc. 1991, 113, 4016-4017. [CrossRef]

66. De Caro, D.; Bradley, J.S. Investigation of the surface structure of colloidal platinum by infrared spectroscopy of adsorbed CO. New J. Chem. 1998, 22, 1267-1273. [CrossRef]

67. Duteil, A.; Queau, R.; Chaudret, B.; Mazel, R.; Roucau, C.; Bradley, J.S. Preparation of organic solutions or solid films of small particles of ruthenium, palladium, and platinum from organometallic precursors in the presence of cellulose derivatives. Chem. Mater. 1993, 5, 341-347. [CrossRef]

68. Kinayyigit, S.; Lara, P.; Lecante, P.; Philippot, K.; Chaudret, B. Probing the surface of platinum nanoparticles with 13 CO by solid-state NMR and IR spectroscopies. Nanoscale 2014, 6, 539-546. [CrossRef] [PubMed]

69. Lara, P.; Martínez-Prieto, L.M.; Roselló-Merino, M.; Richter, C.; Glorius, F.; Conejero, S.; Philippot, K.; Chaudret, B. NHC-stabilized Ru nanoparticles: Synthesis and surface studies. Nano-Struct. Nano-Objects 2016, 6, 39-45. [CrossRef]

70. Martínez-Prieto, L.M.; Cano, I.; Márquez, A.; Baquero, E.A.; Tricard, S.; Cusinato, L.; Del Rosal, I.; Poteau, R.; Coppel, Y.; Philippot, K.; et al. Zwitterionic amidinates as effective ligands for platinum nanoparticle hydrogenation catalysts. Chem. Sci. 2017, 8, 2931-2941. [CrossRef]

71. Martínez-Prieto, L.M.; Urbaneja, C.; Palma, P.; Cámpora, J.; Philippot, K.; Chaudret, B. A betaine adduct of $\mathrm{N}$-heterocyclic carbene and carbodiimide, an efficient ligand to produce ultra-small ruthenium nanoparticles. Chem. Commun. 2015, 51, 4647-4650. [CrossRef]

72. Badia, A.; Gao, W.; Singh, S.; Demers, L.; Cuccia, L.; Reven, L. Structure and chain dynamics of alkanethiol-capped gold colloids. Langmuir 1996, 12, 1262-1269. [CrossRef]

73. Favier, I.; Massou, S.; Teuma, E.; Philippot, K.; Chaudret, B.; Gómez, M. A new and specific mode of stabilization of metallic nanoparticles. Chem. Commun. 2008, 3296-3298. [CrossRef]

74. Silbestri, G.F.; Flores, J.C.; De Jesús, E. Water-soluble N-heterocyclic carbene platinum (0) complexes: Recyclable catalysts for the hydrosilylation of alkynes in water at room temperature. Organometallics 2012, 31, 3355-3360. [CrossRef]

75. Baquero, E.A.; Silbestri, G.F.; Gómez-Sal, P.; Flores, J.C.; De Jesús, E. Sulfonated water-soluble N-heterocyclic carbene silver (I) complexes: Behavior in aqueous medium and as NHC-transfer agents to platinum (II). Organometallics 2013, 32, 2814-2826. [CrossRef]

76. Baquero, E.A.; Flores, J.C.; Perles, J.; Gómez-Sal, P.; De Jesús, E. Water-soluble mono-and dimethyl N-heterocyclic carbene platinum (II) complexes: Synthesis and reactivity. Organometallics 2014, 33, 5470-5482. [CrossRef]

77. Berthon-Gelloz, G.; Buisine, O.; Brière, J.-F.; Michaud, G.; Sterin, S.; Mignani, G.; Tinant, B.; Declercq, J.-P.; Chapon, D.; Markó, I.E. Synthetic and structural studies of NHC-Pt (dvtms) complexes and their application as alkene hydrosilylation catalysts $(\mathrm{NHC}=\mathrm{N}$-heterocyclic carbene, dvtms $=$ divinyltetramethylsiloxane). J. Organomet. Chem. 2005, 690, 6156-6168. [CrossRef]

78. Knight, W.D. Nuclear magnetic resonance shift in metals. Phys. Rev. 1949, 76, 1259-1260. [CrossRef]

79. Van Der Klink, J.; Brom, H. NMR in metals, metal particles and metal cluster compounds. Prog. Nucl. Magn. Reson. Spectrosc. 2000, 36, 89-201. [CrossRef]

80. Dassenoy, F.; Philippot, K.; Ely, T.O.; Amiens, C.; Lecante, P.; Snoeck, E.; Mosset, A.; Casanove, M.-J.; Chaudret, B. Platinum nanoparticles stabilized by CO and octanethiol ligands or polymers: FT-IR, NMR, HREM and WAXS studies. New J. Chem. 1998, 22, 703-712. [CrossRef]

81. Ramírez-Meneses, E.; Erades, L.; Philippot, K.; Lecante, P.; Chaudret, B. Shape control of platinum nanoparticles. Adv. Funct. Mater. 2007, 17, 2219-2228. [CrossRef] 
82. Lara, P.; Casanove, M.-J.; Lecante, P.; Fazzini, P.-F.; Philippot, K.; Chaudret, B. Segregation at a small scale: Synthesis of core-shell bimetallic RuPt nanoparticles, characterization and solid state NMR studies. J. Mater. Chem. 2012, 22, 3578-3584. [CrossRef]

83. Crudden, C.M.; Horton, J.H.; Ebralidze, I.I.; Zenkina, O.V.; McLean, A.B.; Drevniok, B.; She, Z.; Kraatz, H.-B.; Mosey, N.J.; Seki, T.; et al. Ultra stable self-assembled monolayers of N-heterocyclic carbenes on gold. Nat. Chem. 2014, 6, 409-414. [CrossRef]

84. Zhukhovitskiy, A.V.; Mavros, M.G.; Van Voorhis, T.; Johnson, J.A. Addressable carbene anchors for gold surfaces. J. Am. Chem. Soc. 2013, 135, 7418-7421. [CrossRef] [PubMed]

85. Cushing, B.L.; Kolesnichenko, V.L.; O'Connor, C.J. Recent advances in the liquid-phase syntheses of inorganic nanoparticles. Chem. Rev. 2004, 104, 3893-3946. [CrossRef] [PubMed]

86. Lee, C.K.; Vasam, C.S.; Huang, T.W.; Wang, H.M.J.; Yang, R.Y.; Lin, I.J.B.; Lee, C.S. Silver (I) N-heterocyclic carbenes with long N-alkyl chains. Organometallics 2006, 25, 3768-3775. [CrossRef]

87. Bakker, A.; Timmer, A.; Kolodzeiski, E.; Freitag, M.; Gao, H.Y.; Mönig, H.; Amirjalayer, S.; Glorius, F.; Fuchs, H.; Freitag, M. Elucidating the binding modes of N-heterocyclic carbenes on a gold Surface. J. Am. Chem. Soc. 2018, 140, 11889-11892. [CrossRef]

88. Copéret, C.; Kaeffer, N.; Mance, D. N-Heterocyclic Carbene Coordination to Surface Copper Sites in Selective Semihydrogenation Catalysts from Solid-State NMR Spectroscopy. Angew. Chem. Int. Ed. 2020, 59, 2-11. [CrossRef]

89. Ferry, A.; Schaepe, K.; Tegeder, P.; Richter, C.; Chepiga, K.M.; Ravoo, B.J.; Glorius, F. Negatively charged N-heterocyclic carbene-stabilized Pd and Au nanoparticles and efficient catalysis in water. ACS Catal. 2015, 5, 5414-5420. [CrossRef]

90. Ruiz-Varilla, A.M.; Baquero, E.A.; Chaudret, B.; De Jesús, E.; Gonzalez-Arellano, C.; Flores, J.C.; Del Camino, G.A.M. Water-soluble NHC-stabilized platinum nanoparticles as recoverable catalysts for hydrogenation in water. Catal. Sci. Technol. 2020, 10, 2874-2881. [CrossRef]

91. Otting, G. Experimental NMR techniques for studies of protein-ligand interactions. Curr. Opin. Struct. Boil. 1993, 3, 760-768. [CrossRef]

92. Davis, B. Screening Protein-Small Molecule Interactions by NMR; Springer Science and Business Media: New York, NY, USA, 2013; Volume 1008, pp. 389-413.

93. Gossert, A.D.; Jahnke, W. NMR in drug discovery: A practical guide to identification and validation of ligands interacting with biological macromolecules. Prog. Nucl. Magn. Reson. Spectrosc. 2016, 97, 82-125. [CrossRef]

94. Cusinato, L.; Del Rosal, I.; Poteau, R. Shape, electronic structure and steric effects of organometallic nanocatalysts: Relevant tools to improve the synergy between theory and experiment. Dalton Trans. 2017, 46, 378-395. [CrossRef]

95. González-Gálvez, D.; Lara, P.; Rivada-Wheelaghan, O.; Conejero, S.; Chaudret, B.; Philippot, K.; Van Leeuwen, P.W.N.M. NHC-stabilized ruthenium nanoparticles as new catalysts for the hydrogenation of aromatics. Catal. Sci. Technol. 2013, 3, 99-105. [CrossRef]

96. Zahmakiran, M.; Philippot, K.; Özkar, S.; Chaudret, B. Size-controllable APTS stabilized ruthenium (0) nanoparticlescatalyst for the dehydrogenation of dimethylamine-borane at room temperature. Dalton Trans. 2012, 41, 590-598. [CrossRef] [PubMed]

97. López-Vinasco, A.M.; Martínez-Prieto, L.M.; Asensio, J.M.; Lecante, P.; Chaudret, B.; Cámpora, J.; Van Leeuwen, P.W.N.M.; Revert, J.M.M.A. Novel nickel nanoparticles stabilized by imidazolium-amidinate ligands for selective hydrogenation of alkynes. Catal. Sci. Technol. 2020, 10, 342-350. [CrossRef]

98. Rakers, L.; Martínez-Prieto, L.M.; López-Vinasco, A.M.; Philippot, K.; Chaudret, B.; Glorius, F.; Van Leeuwen, P.W.N.M. Ruthenium nanoparticles ligated by cholesterol-derived NHCs and their application in the hydrogenation of arenes. Chem. Commun. 2018, 54, 7070-7073. [CrossRef] [PubMed]

99. Rakers, L.; Grill, D.; Matos, A.L.; Wulff, S.; Wang, D.; Börgel, J.; Körsgen, M.; Arlinghaus, H.F.; Galla, H.-J.; Gerke, V.; et al. Addressable cholesterol analogs for live imaging of cellular membranes. Cell Chem. Boil. 2018, 25, 952-961.e12. [CrossRef]

100. Tegeder, P.; Freitag, M.; Chepiga, K.M.; Muratsugu, S.; Möller, N.; Lamping, S.; Tada, M.; Glorius, F.; Ravoo, B.J. N-Heterocyclic carbene-modified Au-Pd alloy nanoparticles and their application as biomimetic and heterogeneous catalysts. Chem. A. Eur. J. 2018, 24, 18682-18688. [CrossRef] 
101. Kunz, S. Supported, Ligand-Functionalized Nanoparticles: An attempt to rationalize the application and potential of ligands in heterogeneous catalysis. Top. Catal. 2016, 59, 1671-1685. [CrossRef]

102. Ernst, J.B.; Muratsugu, S.; Wang, F.; Tada, M.; Glorius, F. Tunable heterogeneous catalysis: N-heterocyclic carbenes as ligands for supported heterogeneous $\mathrm{Ru} / \mathrm{K}-\mathrm{Al}_{2} \mathrm{O}_{3}$ catalysts to tune reactivity and selectivity. J. Am. Chem. Soc. 2016, 138, 10718-10721. [CrossRef]

103. Palazzolo, A.; Naret, T.; Daniel-Bertrand, M.; Buisson, D.-A.; Tricard, S.; Lesot, P.; Coppel, Y.; Chaudret, B.; Feuillastre, S.; Pieters, G. Tuning the reactivity of a heterogeneous catalyst using N-heterocyclic carbene ligands for C-H activation reactions. Angew. Chem. Int. Ed. 2020, 59, 1-7. [CrossRef]

(C) 2020 by the authors. Licensee MDPI, Basel, Switzerland. This article is an open access article distributed under the terms and conditions of the Creative Commons Attribution (CC BY) license (http://creativecommons.org/licenses/by/4.0/). 